\title{
Large scale diversity reassessment, evolutionary history, and taxonomic revision of the green macroalgae family Udoteaceae (Bryopsidales, Chlorophyta)
}

\author{
Lagourgue Laura ${ }^{1,2,{ }^{*}}$, Payri Claude E. ${ }^{2}$
}

${ }^{1}$ Sorbonne Universités UPMC Univ Paris 06, IFD, 4 Place Jussieu, 75252 Paris Cedex 05, France

2 UMR ENTROPIE (IRD, UR, UNC, CNRS, IFREMER), Institut de Recherche pour le Développement, B.P. A5 Nouméa Cedex Nouvelle-Calédonie 98848, France

* Corresponding author : Laura Lagourgue, email address : laura.lagourgue@ird.fr

\begin{abstract}
:
Udoteaceae is a morphologically diverse family of the order Bryopsidales. Despite being very widespread geographically, this family is little known compared to the closely related Halimedaceae or Caulerpaceae. Using the most extensive Udoteaceae collection to date and a multilocus genetic dataset (tufA, rbcL and $18 S$ rDNA), we reassessed the species diversity of the family, as well as the phylogenetic relationships, the diagnostic morpho-anatomical characters and evolutionary history of its genera, toward a proposed taxonomic revision. Our approach included a combination of molecular and morphological criteria, including species delimitation methods, phylogenetic reconstruction and mapping of trait evolution. We successfully delimited 62 species hypotheses, of which 29 were assigned (existing) species names and 13 represent putative new species. Our results also led us to revise the genera Udotea s.s., Rhipidosiphon s.s. and Chlorodesmis S.s., to validate the genus Rhipidodesmis and to propose three new genera: Glaukea gen. nov., Ventalia gen. nov., and Udoteopsis gen. nov. We also identified two large species complexes, which we refer to as the "Penicillus-Rhipidosiphon-Rhipocephalus-Udotea complex" and the "Poropsis-Penicillus-Rhipidodesmis complex". Using a time-calibrated phylogeny, we estimated the origin of the family Udoteaceae at Late Triassic (ca $216 \mathrm{Ma}$ ), whereas most of the genera originated during Paleogene. Our morphological inference results indicated that the thallus of the Udoteaceae ancestor was likely entirely corticated and calcified, composed of a creeping axis with a multisiphonous stipe and a pluristromatic flabellate frond. The frond shape, cortication and calcification are still symplesiomorphies for most extant Udoteaceae genera and represent useful diagnostic characters.
\end{abstract}

Keywords : Chlorophyta, macroalgae, phylogeny, species delimitation, trait evolution 


\section{Graphical Abstract}

- A reassessment of the Udoteaceae diversity with an unexpected species and genus richness highlighted.

- A taxonomic revision at the genus level is proposed, and the relevance of diagnostic morpho-anatomical characters is re-evaluated.

- An origin of the family Udoteaceae estimated at about 216 Ma (Late Triassic), whereas most of the extant species originated in the Paleogene.

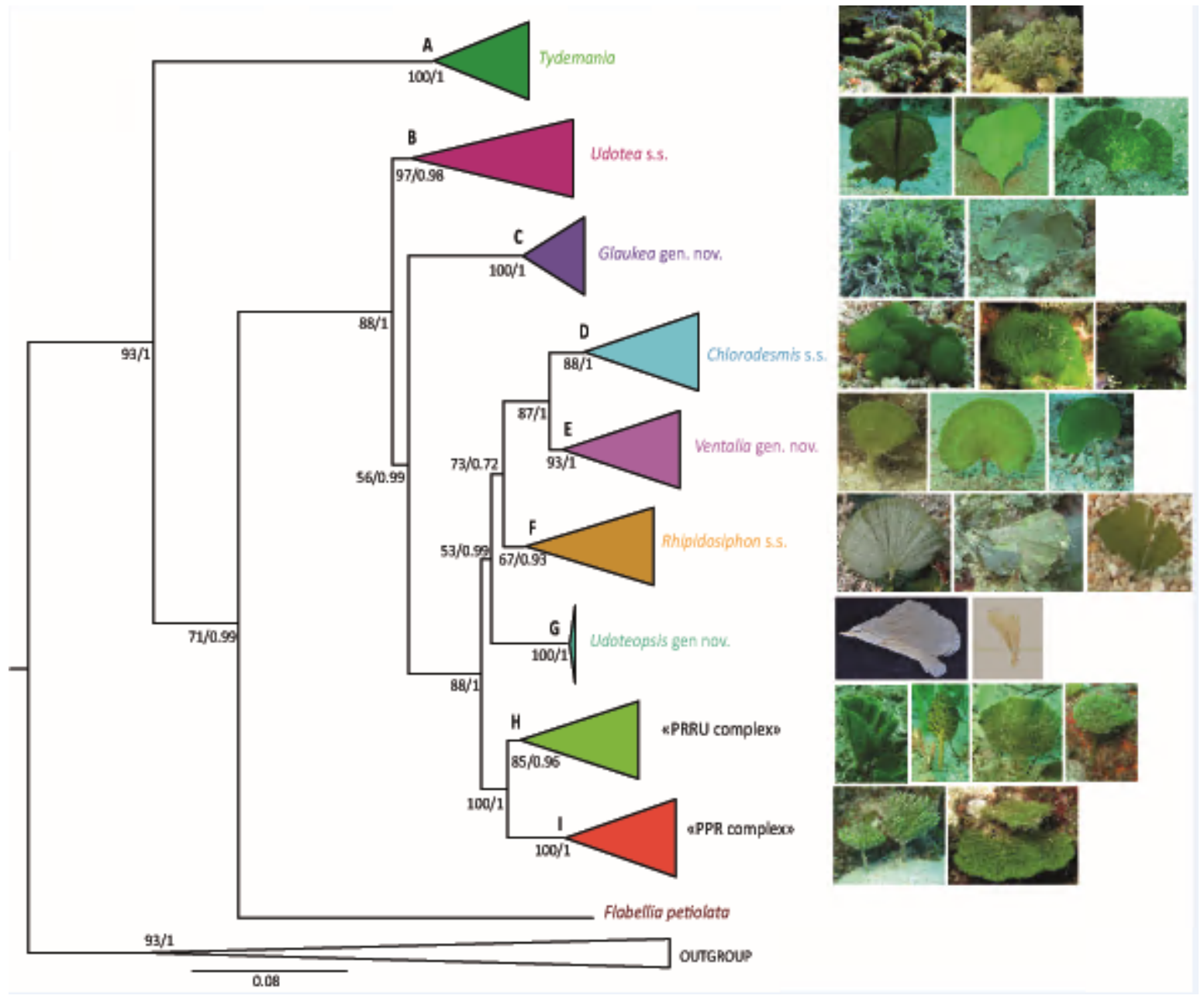

Keywords: Chlorophyta; macroalgae; species delimitation; phylogeny; trait evolution 


\section{INTRODUCTION}

Udoteaceae J. Agardh is a family of green siphonous macroalgae belonging to the order Bryopsidales J. H. Schaffner. The family has a worldwide distribution with representatives occurring in tropical, subtropical and temperate regions throughout the Atlantic, Indian and Pacific oceans as well as in the Red Sea and the Mediterranean Sea. Udoteaceae species are most abundant in reef ecosystems where they play an important ecological function as primary producers, contribute to carbonate fluxes and provide shelter and food to other organisms (Goreau, 1963; Wray, 1977; Ries, 2006; Payri, 2000; Granier, 2012). Currently, the family, which includes both calcified and non-calcified taxa, accounts for eight extant genera and 64 species (Guiry \& Guiry, 2020), if we exclude: 1) synonymized or invalid genera (Ancestria, Neseae, Coralliodendron, Corallocephalus, Espera (syn. of Penicillus); Decaisnella and Geppina (syn of. Udotea); Flabellaria J. V. Lamouroux (syn. of Flabellia); Rhipidodesmis (syn. of Chlorodesmis); Poropsis Nizamuddin (uncertain) and Flabellaria Lamarck (nom. illeg.)); and 2) genera previously shown to be unrelated to the Udoteaceae (e.g., Botryodesmis, Pseudochlorodesmis and Siphonogramen (Verbruggen et al. 2009a); Boodleopsis, Callipsygma and Johnson-sea-linkia (Cremen et al., 2019); Chloroplegma (syn. of Avrainvillea; Wade et al 2018), Rhipiliella (probably belonging to Rhipiliaceae; Dragastan et al., 1997). A total of 20 species included in these genera can then be subtracted from the overall species diversity previously included in the Udoteaceae.

Although they are all siphonous and composed of a unique giant and multinucleate tubular cell, Udoteaceae genera are remarkable for their morphological diversity. Their forms range from dichotomous filaments, single or grouped in tufts, to more 
complex thalli with characteristic frond morphologies (e.g., capitate for the genus Penicillus or flabellate for Udotea).

Since its publication by Agardh (1887), the most comprehensive work on Udoteaceae was published by Gepp \& Gepp (1911). Several authors have subsequently contributed to improving knowledge of species diversity (Farghaly, 1980; Meinesz, 1980; Littler \& Littler, 1990a and b; Vroom et al., 1998; Collado-Vides et al., 2009), and with the discovery of new species and the increase in morphological information, several authors have discussed the need to redefine genera (Agardh, 1887; Gepp \& Gepp, 1911; Nizamuddin, 1963; Farghaly, 1980; Littler \& Littler, 1990a; Dragastan et al., 1997). The few molecular-based studies conducted on Udoteaceae have highlighted conflicts between morphological and molecular information, revealing polyphyletic genera (i.e., Chlorodesmis, Penicillus, Poropsis, Rhipocephalus, Rhipidosipon and Udotea) and unresolved phylogenetic relationships for most taxa (Kooistra, 2002; Lam \& Zechman, 2006; Curtis et al.; 2008; Verbruggen et al., 2009a and b; Coppejans et al., 2011; Lagourgue et al., 2018; Wade \& Sherwood, 2018; Cremen et al., 2019). When reassessing the classification of the order Bryopsidales using the chloroplast genome, and to avoid proliferation of new families with a parsimonious and practical purpose, Cremen et al. (2019) proposed to abandon the Udoteaceae family in favor of tribe Udoteae, which the authors placed in family Halimedaceae Link together with other families such as Rhipiliaceae Kützing and Pseudocodiaceae L. Hillis-Colinvaux, and the genus Halimeda. However, we believe that this decision overlooked morpho-anatomical variability and existing genera and species diversity in the clade that we therefore prefer to maintain as the family Udoteaceae. Indeed, studies on closely related families (Halimedaceae, Caulerpaceae 
Kützing) revealed unexpected species diversity (Verbruggen et al., 2005a and b; Sauvage et al., 2013) and highlighted the existence of new lineages at the family level with low morphological differentiation (Sauvage et al., 2016; Verbruggen et al., 2017, Cremen et al., 2019). This contrasts sharply with the family Udoteaceae, whose rich species and genus diversity remains to be reassessed. The genetic data available for Udoteaceae is fragmentary (122 sequences for tufA, $r b c L$ and $18 \mathrm{~S}$ rDNA) and is limited to 26 of the current 64 species, often with only one sequenced marker per specimen and some level of misidentification. Numerous tools have been developed to assess diversity and delimitate species that are now largely applied across various macroalgal taxa. These include tree-based methods such as the General Mixed Yule Coalescent (GMYC) (Pons et al., 2006) and its Bayesian implementation, bGMYC (Reid \& Carstens, 2012), the Poisson tree process model (PTP, Zhang et al., 2013) and the Multi-rate version, mPTP (Kapli et al., 2017), as well as methods directly relying on genetic distances, such as the Automatic Barcode Gap Discovery (ABGD, Puillandre et al., 2012a). For robust species hypothesis, several authors have recommended to search for congruence between the different methods applied to several genes (Carstens et al., 2013; Carstens \& Knowles, 2007; Dupuis et al., 2012; Leliaert et al., 2014; Puillandre et al., 2012b; Rannala, 2015) and to compare molecular-based partitions with non-genetic data (Carstens et al., 2013; Carstens \& Knowles, 2007; Fujita et al., 2012; Talavera et al., 2013; Wiens, 2007).

Additionally, the large morphological diversity of Udoteaceae genera and species illustrates a complex pattern of diversification within the Bryopsidales, which has led to several hypotheses on the morphology of its ancestor (Gepp \& Gepp, 1911; Littler \& Littler, 1990a; Vroom et al., 1998; Kooistra, 2002). To date, these hypotheses 
remain untested (e.g., calcified or uncalcified ancestor), and the family represents an original and interesting case study for an evolutionary approach. Analytical methods, including statistics (Dubois, 2007; Rabosky et al., 2013) make it possible to analyze the phylogenetic evolution of morphological characters and the genotype/phenotype correlation by measuring, for example, the phylogenetic signal of morphological characters. The phylogenetic inference of trait evolution is another relevant approach, which has been little used for the study of macroalgae, with only three studies applied to green siphonous macroalgae (Codium (Verbruggen et al., 2007); Halimeda (Verbruggen et al., 2009c) and Pseudocodium (Payri \& Verbruggen, 2009)). By using this approach, it is possible to explore the evolution of morpho-anatomical characters both in time and across lineages and to test hypotheses about the ancestral state of various characters. It is then possible to highlight relevant characters to discriminate groups of species or specific morphological patterns, which together allow a better understanding of the evolutionary history of the taxa studied. Phylogenetic inference of trait evolution is therefore of particular interest, among others, for integrative taxonomy approaches based on data of various origins (molecular, morphological, ecological, functional data, etc.) (Dayrat, 2005; Schlick-Steiner et al., 2010; Garbino, 2018).

Using the largest Udoteaceae taxon sampling to date and a multilocus genetic dataset (tufA, $r b c L$ and $18 \mathrm{~S}$ rDNA), we aim to reassess the species diversity of the family, the phylogenetic relationships, the diagnostic morpho-anatomical characters of its genera, as well as the morphological and evolutionary history of the lineages, and to provide the necessary taxonomic revisions. To reach these objectives, we use a combination of molecular and morphological approaches, including species delimitation methods, phylogenetic

This article is protected by copyright. All rights reserved. 
reconstruction, time-calibrated analyses and inference on the evolution of morpho-anatomical characters.

\section{Material and Methods}

\subsection{Sampling}

Samples were collected using SCUBA down $60 \mathrm{~m}$ deep or snorkeling from various localities worldwide including in the Atlantic, Indian and Pacific oceans as well as the Red Sea and the Mediterranean Sea. A total of 644 samples were processed in this study, including 527 samples collected by the authors and 117 obtained through collaborations (Table S1 in Supporting Information). Vouchers were pressed-dried on herbarium sheets and housed in various herbariums, including NOU in New Caledonia, PC in France and GENT in Belgium (herbarium abbreviations follow Thiers (2019), continuously updated). Subsamples of the fresh specimens were preserved in a 5\% formaldehyde solution in sea water for later morpho-anatomical observations and both in 95\% ethanol and silica gel for later DNA extractions.

\subsection{Morphological characters and analyses}

Morpho-anatomical observations were made on fragments preserved in formaldehyde or directly on herbarium specimens. Calcified specimens were previously treated with a 5\% hydrochloric acid solution for 1 to 2 hours. Observations and measurements were made using an A2 Imager microscope (Axio) fitted with a Canon EOS-100D camera. Photos of macroscopic characters were made using a binocular microscope (Wild M3Z) equipped with a Canon EOS-700D camera. All morpho-anatomical 
characters reported in previous studies were considered (Gepp \& Gepp, 1911; Littler \& Littler, 1990a, b; Ducker, 1967; Coppejans et al., 2011). A selection of 30 discrete (10 binary and 20 multivariate) and two continuous characters were analyzed, including morphological (e.g., thallus, stipe, frond shape, attachment type) and anatomical characters (e.g., siphon diameter and form, branching type, secondary structures). For each species, the different states of character were encoded into a matrix without ordination or weight. All character states are synthesized in Supporting Information (Data S1).

\subsection{DNA sequencing and alignment}

Samples were extracted using either the Plant mini Kit (Qiagen Inc, Valencia, CA, USA) (for Chlorodesmis), the Blood and Tissue Kit (Qiagen Inc, Valencia, CA, USA) (for calcified genera, i.e., Udotea, Penicillus, Rhipocephalus, Tydemania) or the CTAB protocol (for Rhipidosiphon and Poropsis). Two chloroplast markers were targeted, tufA and $r b c L$, as well as the 18S rDNA nuclear gene using previously published primers (Händeler et al., 2010; Kooistra, 2002; Lam \& Zechman, 2006; Verbruggen et al., 2009b) (see Table S2). PCR reactions were conducted in a final volume of $25 \mu \mathrm{L}$ including $12.5 \mu \mathrm{L}$ of AmpliTaq Gold 360 Master Mix (Applied Biosystems), $1 \mu \mathrm{L}$ of each primer $(10 \mu \mathrm{M}), 0.75 \mu \mathrm{L}$ of dimethylsulfoxyde (DMSO), 1 $\mu \mathrm{L}$ of bovine serum albumin (BSA), $2.5 \mu \mathrm{L}$ of DNA and $6.25 \mu \mathrm{L}$ of ultra-pure water. PCR programs follow Lagourgue et al. (2018). The Sanger sequencing reaction was carried out using $20 \mu \mathrm{L}$ of PCR product by Genoscreen (Lille, FRANCE). Sequences were then edited in Geneious version 7.1 .9 (http://www.geneious.com, Kearse et al., 2012) and aligned for each marker separately using the MUSCLE algorithm available in the software. Sequences obtained from collaborators and Genbank were added to 
our dataset. As far as possible, a maximum of specimens from the type localities have been included in the analyses. When none was available, Genbank sequences that did not come from the type localities were considered with caution for the risk of misidentification by previous authors.

\subsection{Composition of the datasets}

The two chloroplasts markers, tufA and $r b c L$, known for their discriminatory power at the species level in green macroalgae (Leliaert et al., 2014; Saunders \& Kucera, 2010; Verbruggen et al., 2009b) were selected for species delimitation analyses. Maximum Likelihood (ML) and Bayesian ultrametric trees were reconstructed from single marker alignments, after removing identical haplotypes using the Collapsetypes v4.6 perl script (Chesters, 2013). Outgroup taxa (see Table S3) were also removed before running species delimitation analyses.

In addition, two different concatenated multilocus matrices (tufA, rbcL and $18 \mathrm{~S}$ rDNA) were compiled to perform phylogenetic analyses. The first was composed of several specimens per species, for which at least two of the three markers were available, to assess the taxonomic position and composition of the different Udoteaceae genera. The second dataset corresponded to a selection of one specimen per species (as defined by the species delimitation approach) and was intended for evolutionary analyses and time-calibrated phylogeny. A total of ten outgroup species were added to the second dataset to ensure proper phylogenetic calibration (see Table S3).

This article is protected by copyright. All rights reserved. 


\subsection{Tree inference}

Prior to the phylogenetic analyses, each dataset was analyzed with Partition Finder v1.1.0 (Lanfear et al., 2012) to determine the best partition schemes and the most suitable evolutionary models based on the Akaike information criterion (AIC). As the sequencing success was uneven between the two parts of the $r b c L$ gene, we chose to consider them separately (as rbcL5' and rbcL3') to improve the modelling.

For each dataset, ML trees were reconstructed using RAXML (Stamatakis, 2014) through the CIPRES web portal (Miller et al., 2010). ML analyses were launched using the "rapid bootstrapping and search for the best-scoring ML tree" algorithm, the GTR $+1+\mathrm{G}$ evolutionary model and 1,000 bootstrap (bs) iterations (Stamatakis et al., 2008).

Bayesian ultrametric trees (for species delimitation analyses) were estimated using BEAST (Drummond et al., 2012) through the CIPRES web portal. Two independent analyses of 30 and 40 million generations were run for tufA and $r b c L$, respectively, and sampled every 1,000 generations. The Likelihood ratio test, using MEGA 6 (Tamura et al., 2013), rejected the null clock hypothesis; trees were, therefore, estimated using a relaxed lognormal molecular clock (Drummond et al., 2006) with a coalescent constant size tree prior as recommended by Monaghan et al. (2009).

The Bayesian inference (BI) on the multilocus matrix (tufA, $r b c \mathrm{~L}$, and 18S) composed of several specimens per species, was performed using MrBayes v.3.2 (Ronquist \& Huelsenbeck, 2003) through the CIPRES portal. The analysis was carried out in two 
independent runs of four incrementally heated chains of 50 million generations, sampled every 1,000 generations, with a burn-in set at $10 \%$.

The time-calibrated phylogeny was carried out using BEAST v.2.5.0 (Bouckaert et al., 2014) through the CIPRES web portal. It was estimated under a Calibrated Yule model (Heled \& Drummond, 2012) and a relaxed lognormal molecular clock (Drummond et al., 2006). Two independent analyses were run for 75 million generations and sampled every 10,000 generations.

For all Bayesian analyses, each run output was checked in Tracer v.1.5 (Rambaut \& Drummond, 2007) to confirm the convergence of the Markov Chains Monte Carlo (MCMC) and that effective sample size (ESS) values were all above 200 , before computing a consensus topology and posterior probabilities. For Beast trees, the outputs were combined using Log Combiner (included in the BEAST package), removing the first $10 \%$ generations as burn-in. The Maximum Clade Credibility Tree (MCCT) was calculated using Tree Annotator (included in the BEAST package).

Outgroup taxa, partition schemes, evolutionary models, and reconstruction parameters for all ML and BI trees are detailed in Table S3 (Supporting Information).

\subsection{Species delimitation methods}

Five species delimitation methods were used to assess the Udoteaceae species diversity based on the chloroplast markers: ABGD, GMYC, bGMYC, PTP and mPTP. The species delimitation process then consists of comparing the different primary species hypotheses (PSHs) resulting from the species delimitation methods, and searching for congruence between the different markers analyzed to define secondary

This article is protected by copyright. All rights reserved. 
species hypotheses (SSHs). In case of conflicts, a majority rule was applied, and the most prevalent PSH was selected. Morpho-anatomical observations were then compared to molecular-based species hypotheses to confirm SSHs, as well as to assign species names when possible.

The ABGD method was applied to both tufA and $r b c L$ alignments through the website: http://www.abi.snv.jussieu.fr/public/abgd/abgdweb.html. The Kimura model (relative minimum gap width $(\mathrm{X})=1$ ) was used for the tufA analysis, while the JC (X $=0.5)$ and the SD models $(\mathrm{X}=1)$ were preferred for analysing the $r b c L 5$ ' and $r b c L 3$ ' fragments, respectively. All other parameters were used with default values. GMYC was performed using the package "splits” in R (R Development Core Team, 2019) on bayesian MCCTs. The bGMYC method was applied using the "bGMYC" package (Reid \& Carstens, 2012) also in the R environment on a subsample of 100 BEAST trees. The analyses were carried out on 10,000 and 15,000 MCMC generations, sampled every 100 generations, for tufA and $r b c L$, respectively. The PTP method was conducted through the Exelixis Lab web server (http://sco.hits.org/exelixis/web/software/PTP/index.html) on the ML rooted tree and run for 500,000 generations for both tufA and $r b c L$, sampling every 1,000 generations and without considering the outgroups. Finally, mPTP was carried out on the mPTP web server (http://mPTP.hits.org) both on bayesian MCCTs and ML rooted tree with default settings for all parameters.

\subsection{Time calibration points}

For reconstruction of the time-calibrated phylogeny, three calibration points derived from fossil information were used (Table S4): 1) Halimeda soltanesis - 250 million of 
years (Ma) (Poncet, 1989), 2) Caulerpa sp. - 280 Ma (Gustavson \& Delevoryas, 1992), and 3) Pseudopenicillus aegaeicus - Late Triassic (Dragastan et al., 1997). Due to the lack of convergence of runs and low ESS values during preliminary analyses, likely because of bias in paleontological dating and/or erroneous phylogenetic placement, we choose not to consider the age of the fossil Udotea palmetta (Fiore, 1936). These calibration points were set with uniform distributions and minimal age corresponding to the estimated age of the fossil (cf. Table S4). Three additional calibration points were selected from the study of Verbruggen et al. (2009b): 1) Bryopsidales root - 456 Ma, 2) Crown of Core Halimedineae - 391 Ma, and 3) Crown of Halimedaceae + Pseudocodiaceae + Udoteaceae -273 Ma. They were constrained using corresponding ages and normal distributions ( $c f$. Table S4 for more details).

\subsection{Phylogenetic signal and correlation analyses}

The phylogenetic signal is based on the assumption that phylogenetically related organisms tend to resemble each other phenotypically. In this study, the phylogenetic signal was measured to identify whether a morphological trait followed this trend or appeared more labile and unpredictable. Our aim was to assess the relevance of each trait to provide revised morphological descriptions. For the continuous characters, the phylogenetic signal (PS) was estimated with Blomberg's K (Blomberg et al., 2003) and Pagel’s K (Pagel, 1999) statistics using the "phylosig” function of the phytools package (Revell, 2012) in R. These two measures quantify trait variation with respect to the "random walk" model of the Brownian motion (BM). If $K=1$, the PS is strong and in accordance with the BM model; if $\mathrm{K}<1$, the PS is lower than under the BM model; if $\mathrm{K}=0$, there is no PS (the trait evolves independently of the phylogeny); if $\mathrm{K}>1$, the PS is stronger than expected under the BM model (close species are more 
similar than expected under the BM). If $\kappa$ equals or is close to 0 , there is no PS; if $\Lambda=1$, the PS is strong (the trait evolves following the BM model); if $0<\kappa<1$, a PS exists, but the trait does not evolve according to the BM model and probably follows another process (e.g., Ornstein-Uhlenbeck, OU). The evolutionary model best adapted to the trait evolution (BM, OU or the "early-bust” model) was tested using the “geiger” package (Harmon et al., 2008). For discrete characters, the PS was estimated with the phylogenetic D statistic (Fritz \& Purvis, 2010) using the function "phylo.d” of the “caper” package (Orme et al., 2013) in R. The D statistic calculates the ratio between the sum of the sister clade differences, from which the BM expectation is extracted, and the difference between a random estimate and the BM expectation. If $\mathrm{D}<0$, the trait has a strong PS; if $\mathrm{D}>0$, the trait has a PS lower than expected with the BM model.

The correlation between discrete characters was computed using the function "fitpagel” of the "phytools" package (Revell, 2012). For continuous characters, the phylogenetic generalized least squares (PGLS) was calculated with the "nmle" package.

Multivariate discrete characters were converted to binary for estimating the D statistic (PS) and Pagel's test of correlation (see Data S1 for transformation).

\subsection{Ancestral states reconstruction}

To infer trait evolution on the phylogeny, we used the time-calibrated phylogeny of the family reconstructed from the concatenated multilocus matrix and the characters matrix produced from the morpho-anatomical observations. Ancestral state estimations were computed using the "phytools” package (Revell, 2012). The 
“contMap” function was used for the continuous characters, while estimations for discrete (binary and multivariate) characters were calculated using the “make.simmap” function with 1,000 simulations. Equal probability was applied to each state of character that was either missing or had a non-applicable (N.A.) value.

Based on the combination of molecular and morpho-anatomical data and using a likelihood criterion and a defined number of iterations, these analyses reconstruct the ancestral state estimated at each node for each character selected. The ancestral state estimation, therefore, represents the probability of the different states of a given character at each node of the tree. This allows identifying the status and taxonomic relevance of the morphological characters studied. Synapomorphies (i.e., derived states shared by at least two taxa and inherited from a common ancestor) are useful in the taxonomic review process at genus-level and for documenting diagnoses. Homoplasies (i.e., similar states of character found between different species, which do not originate from the same ancestor) cannot be used for species diagnoses, but provide information on the evolutionary history of a particular trait and allow to explore its evolutionary pattern.

\section{RESULTS}

\subsection{Genetic variability}

A total of 1,056 sequences were obtained in this study, including 518 tufA sequences (852 base pairs, bp), 397 rbcL sequences (1,365 bp-long, including 763 bp of the rbcL5' fragment and 602 bp of the rbcL3' fragment), and 141 18S rDNA sequences (1,226 bp). The tufA dataset had 179 unique haplotypes and 482 variables sites (57.24 \%). The $r b c L$ dataset had 139 unique haplotypes and 496 variables sites (36.3 \%), 
with the $r b c L 5$ ' and $r b c L 3$ ' fragments accounting for 287 (37.61\%) and 209 variable sites (34.72\%), respectively. Finally, the 18S rDNA dataset had 222 variables sites (18.10\%). From our dataset, tufA appeared more variable than $r b c L$. The $r b c L 5 '$ fragment was more variable than the $r b c L 3$ ' fragment, which corroborates the results of Lagourgue et al. (2018) for the Caribbean Udoteaceae species, and contrasts with other studies on Bryopsidales families, for which the $r b c L 3$ ' fragment appeared more variable and informative than rbcL5' (Saunder \& Kucera, 2010).

A total of 422 sequences have been submitted to the Genbank under accession numbers MT324398-MT324484 for 18S rDNA sequences, MT339592-MT339713 and MT456567-MT456591 for $r b c L$ sequences and MT340305-MT340496 for tufA sequences (see Table S1).

\subsection{Species delimitation and name assignment}

3.2.1 Primary Species Hypotheses (PSHs): Results obtained with the five delimitation methods for the tufA and $r b c L$ datasets are summarized in Table 1 and are available in more detail in Supporting Information (Figures S1 \& S2 and Data S2). The PSHs support values of the hPTP method and the a posteriori probabilities (PP) of bGMYC partitions are also given in Supporting Information (Data S3 \& S4 and Tables S5 \& S6, respectively). The five methods recovered between 39 and 53 PSHs for tufA, and between 48 and 56 PSHs for $r b c L$. Among those, a total of 23 and 35 PSHs were shared between the five methods for tufA and $r b c L$, respectively. Several incongruences were found between the five methods results for tufA as well as for $r b c L$ (Figures S1 and S2 respectively). For the tufA dataset, most discrepancy was found for the delimitation of Udotea spp. (clades 24 to 29 and clades 38 \& 39) and 
Chlorodesmis spp. (clades 17 \& 59) (Fig. S1). Similarly, for the $r b c L$ dataset, most incongruences were also found for delimitating some Udotea spp. (clades 26 to 29) and Chlorodesmis species (clades 17, 21,22 and 59) (Fig. S2). For both markers, the GMYC and bMGYC methods were the most conservative, whereas hPTP tended to over-split clades.

\subsubsection{Secondary Species Hypotheses (SSHs) and assignment: Based on the} common PSHs of the five species delimitation methods (see Table S7) or the majority rule, a total of 50 and 54 SSHs were retained for tufA and $r b c L$, respectively, out of which 42 SSHs were common between the two markers. Most of them (24) were congruent between markers and with morpho-anatomical observations and were, therefore, retained as valid species hypotheses. Some of the remaining SSHs, which were not congruent between markers, were resolved using morpho-anatomical observations (15), while others require further data and analysis (3). Table S8 (Supporting Information) provides details on the incongruence resolution process, conclusions and species assignment.

Altogether, 62 SSHs were retained for the two markers combined. Among these, 29 SSHs were identified to species level, five SSHs still require confirmation, and 13 SSHs could represent species new to science. Another 15 SSHs were represented by sequences downloaded from the Genbank or provided by collaborators, for which morpho-anatomical data were unavailable to confirm species name assignment. Genera and species name assigned to the different SSHs are detailed in the Supporting Information (Figures S1 \& S2, Table S1).

This article is protected by copyright. All rights reserved. 


\subsection{Phylogenetic relationships and evolution}

Our concatenated multilocus matrix (3,443 bp) included sequences for a total of 145 specimens, which represented 43 genetically delimited species from several localities around the world from which specimens had never been sequenced. The ML and BI phylogenies resulting from our analyses (Fig. 1) provide new insights into the phylogenetic relationships of Udoteaceae taxa. They produced a total of ten well supported "terminal” clades corresponding to five Udoteaceae genera recorded as current taxonomically by Guiry \& Guiry (2020) (i.e., Udotea, Rhipidosiphon, Chlorodesmis, Tydemania, Flabellia). Our results confirmed the polyphyly and paraphyly of the genera Udotea, Chlorodesmis, Rhipidosiphon, Rhipocephalus, and Penicillus as already pointed out in previous studies (Kooistra, 2002; Lam \& Zechman, 2006; Curtis et al.; 2008; Verbruggen et al., 2009a and b; Coppejans et al., 2011; Lagourgue et al., 2018; Wade \& Sherwood, 2018; Cremen et al., 2019). Only Tydemania and the monospecific genus Flabellia were monophyletic. The genus Poropsis is represented by only one species in this multilocus phylogeny, therefore we could not confirm its monophyly (but see the multiples Poropsis lineages retrieved in gene trees used for species delimitation analyses (Fig. S1 \& S2), and which do not form a monophyletic clade). Although similar conclusions were reported in the literature previously, limited data and unresolved phylogenetic relationships prevented the authors from drawing taxonomic conclusions (Kooistra, 2002, Curtis et al., 2008, Lam \& Zechman,2006; Verbruggen et al., 2009b, Lagourgue et al., 2018). In our analyses, the family Udoteaceae was monophyletic (as defined in the introduction) with high node support (bs: 93; PP: 1) (Figure 1.A). This result contrasts with previous studies where Tydemania was more closely related to Pseudocodiaceae than 
Udoteaceae (Verbruggen et al., 2009b; Sauvage et al., 2016) but corroborates the results of Cremen et al. (2019) (see nevertheless the differences between the chloroplast genes tree (tufA and $r b c L$ ) (Figures S3) which is similar to the concatenated multilocus topology (Fig. 1), and the nuclear 18S rDNA gene tree (Figure S4), where Udoteaceae is not monophyletic (Tydemania and Flabellia branch with Pseudocodium species, although not supported). Here, using node support, the phylogenetic position of type species, the congruence of morphological characters, original diagnoses, published observations and/or proposals, as well as the ancestral character reconstruction, we selected nine clades (A-I, collapsed in Figure 1.B) on which we based our taxonomic revision proposal. Our findings led us to consider clades A, B, D and F, which contained type species for Tydemania, Udotea, Chlorodesmis and Rhipidosiphon, respectively, as representatives of current genera, for which we propose to redefine the taxonomic boundaries. Our data also indicate that clades C, E, and G represent lineages requiring the establishment of new genera (Glaukea gen. nov., Ventalia gen. nov. and Udoteopsis gen. nov., respectively), while the taxonomic status of clades $\mathrm{H}$ and I (the "Penicillus-Rhipidosiphon-RhipocephalusUdotea (PRRU) complex” and the "Poropsis-Penicillus-Rhipidodesmis (PPR) complex”, respectively) remains unclear (see further below for discussion and diagnoses).

The time-calibrated phylogeny of the family Udoteaceae was reconstructed from the concatenated multilocus matrix (tufA, $r b c L$ and $18 \mathrm{~S}$ rDNA) and results are shown in Figure 2. This tree is similar to that shown in Figure 1 and node support is higher for the Bayesian inference than the maximum likelihood method. The revised and new genera (Chlorodesmis s.s., Rhipidosiphon s.s., Udotea s.s., Glaukea gen. nov., 
Ventalia gen. nov. and Udoteopsis gen. nov.) were all monophyletic with strong node support (bs > 90; PP >0.98) (but see the nuclear tree, where Rhipidosiphon is polyphyletic; Fig S4)). Results indicate a divergence between the families Halimedaceae and Pseudocodiaceae/Udoteaceae around 288 Ma (Permian, Paleozoic), while the divergence between the families Pseudocodiaceae and Udoteaceae is around 246 Ma (Late Triassic, Mesozoic). The origin of the Udoteaceae is estimated at about 216 Ma (Late Triassic), but its diversification began around 109 Ma (Early Cretaceous). The most recent speciation event is dated at 3.5 Ma, but most of the extant species originated from diversification events during the Cenozoic (from ca 59 Ma) (Figure 2).

\subsection{Phylogenetic signal, correlation and ancestral reconstructions of morpho- anatomical characters}

The analysis of morphological characters according to the phylogeny and the ancestral reconstructions allowed us to understand the ancestral character states better and to identify those relevant for our taxonomic proposal and revision.

Analysis of the phylogenetic signal for the two continuous traits by the Pagel's $\lambda$ test indicated the presence of a strong phylogenetic signal following a BM model for the stipe siphon diameter and a phylogenetic signal according to a model other than a BM for the frond siphon diameter (Tables S9). The Blomberg's K test also found a phylogenetic signal for both traits, but weaker than in a BM model (Table S9). Of the 27 discrete characters, 17 had a phylogenetic signal (Table S10), while 10 had no or weak phylogenetic signal. The highest scores (D statistics) were found for: growth mode, type of constrictions and absence or presence of a stipe $(-2.05,-1.25$ and -0.96 , 
respectively); the lowest PS values were found for: stipe ramification (1.04), type of dichotomies (1.36) and stipe siphon aspect (1.79). Overall, the phylogenetic signal analyses revealed strong correlations with the phylogeny for the majority of characters studied. Still, several of those traditionally used to distinguish between Udoteae genera had a weak PS, including stipe shape, frond composition, branching pattern, siphon aspect, type of dichotomy and presence or absence of constrictions. On the other hand, the external habit or the type of constriction, which are characters rarely considered, appeared remarkable for their strong phylogenetic signal. Similarly, calcification and thallus cortication also had strong PS, which confirms their taxonomic relevance for the classification of Udoteaceae genera.

Our analyses of trait correlations also provided several interesting results which are detailed in Table S11 and Data S5 (Supporting Information).

Finally, the ancestral state reconstruction results are provided in Supporting Information (Data S5) with a summary of correlated characters, ancestral state estimation and the putative synapomorphies, symplesiomorphies or homoplasies. Table 2 reports the results for discrete characters that are the most relevant because 1 ) they show a PS; 2) the ancestral state could be estimated for the Udoteaceae ancestor; and 3) homoplasies, synapomorphies or symplesiomorphies could be identified (see Table S12 for these results for all the characters studied). Figure 3 presents ancestral state reconstruction of four characters, that we consider the most important for understanding the evolution of the Udoteaceae and revising the taxonomy of its genera. Frond shape (Fig.3. A), thallus cortication (Fig 3.B), presence or absence of calcification (Fig. 3.C) and secondary structures on frond siphons (Fig. 3.D) (all other characters are presented in Data S5).

This article is protected by copyright. All rights reserved. 
The ancestral state (plesiomorphic) was identified for a total of 26 characters (Table S12). We also found several homoplasies (convergent or parallel), as well as cases of regression or synapomorphies, providing important information on the evolutionary trajectories of the different characters. Additionally, we found that several characters states traditionally referenced in genus diagnoses appeared to represent varying degrees of homoplasy. This is particularly true for the presence of pores on the calcified surface of siphons (e.g., Rhipidosiphon s.s., Penicillus, Poropsis), the alignment of dichotomies (Rhipidosiphon), the capitate frond of "Penicillus" (Figure 3.A), or some characters used to identify species such as the branching of the stipe (e.g., Flabellia petiolata, Udotea dixonii, etc.), and the presence of descending lateral siphons (Udotea glaucescens, R. lewmanomontiae) (Data S5). Our results also reveal, for the first time, that many states of character, which used to be considered relevant and diagnostic of genera in previous Bryopsidales studies (e.g., the flabellate form, the presence of a stipe, total cortication, or total calcification) actually represent symplesiomorphies within the family Udoteaceae (i.e., states inherited from the family's ancestor and maintained throughout evolution) (Fig. 3. A. to D and Data S5). The presence of these ancestral states (plesiomorphic) is contrasted between genera, but they often still represent the majority of the states observed. The most symplesiomorphic genera are Flabellia, Udotea s. s. and Glaukea gen. nov. Conversely, the genera with the most derived states (homoplasies and synapomorphies) are Tydemania, Chlorodesmis s.s. and Rhipidodesmis s.s.

All major findings for taxonomical purpose are reported for each genus in the following sections (4.3) and corresponding figures (see Figures 4, 6, 7 and 9) and are also discussed in sections 4.2.1 to 4.2.5.

This article is protected by copyright. All rights reserved. 


\section{DISCUSSION}

\subsection{Udoteaceae phylogenic evolution and diversity}

The topology of the time-calibrated phylogeny (Figure 2), based on one representative per species, appeared similar to our comprehensive ML phylogeny (Fig. 1) and the proposed revised genera were all monophyletic with strong node support (bs > 90; $\mathrm{PP}>0.98$ ). According to our results, the origin of Udoteaceae dates back to about 216 Ma (Late Triassic), which corroborates the work of Verbruggen et al. (2009b) and the calibration points used for the reconstruction. The divergence between the families Halimedaceae and Udoteaceae/Pseudocodiaceae is estimated to about $288 \mathrm{Ma}$, which corresponds to the Permian (Paleozoic) and Udoteaceae latter diverged from Pseudocodiaceae during the Late Triassic (ca 246 Ma, Mesozoic). Most of the Udoteaceae genera originated during the Paleogene (i.e., between ca 66 and $23 \mathrm{Ma}$ ) and the most recent speciation event was estimated around 3.5 Ma (Figure 2).

Our results also shown that for taxa of the family Udoteaceae, tufA and $r b c L 5$ ' alone appear sufficient to assess the variability at species-level and can be used as "barcodes". However, for a larger genetic or phylogenetic analysis (several families or the order Bryopsidales), we recommend using tufA, and the whole $r b c L$ marker (or the $r b c L 3$ ' fragment instead of the $r b c L 5$ ') so that results can be compared to previous studies. In contrast, the $18 \mathrm{~S}$ rDNA was less variable than the chloroplast markers and, therefore, does not represent a good choice for species delimitation analyses.

Our results also demonstrate that the family Udoteaceae has high morphological complexity and large species diversity, although this is not homogeneous across clades. Kooistra (2002) had already pointed out to different genetic and morphological 
patterns within the family Udoteaceae with: 1) fully corticated taxa being morphologically similar ("poor" in diversity), and corresponding to older lineages with slower phenotypic diversification; and 2) uncorticated genera showing rapid cladogenesis with considerable phenotypic changes between related species. This latter case of diversification is found mainly in the "PRRU complex". The complex is monophyletic and geographically restricted. However, it has many homoplasies with other taxa outside the clade that are geographically disconnected, which illustrates parallel genetic and morphological evolutions. The large morphological diversity of the Udoteaceae could thus be interpreted as a phenotypic evolvability (i.e., the ability of lineages to evolve with the production of morphological and ecological novelties) that promotes speciation (Pigliucci, 2008; Adamowicz et al., 2008).

Finally, the analysis of the evolutionary history of the Udoteaceae provides a better understanding of its very significant diversity, both in terms of species and genera, which has long been underestimated but which is demonstrated here, through our results. Although there is no family or tribe concept that is commonly accepted, we question the need for the revisions proposed by Cremen et al. (2019), where such a species and genus rich family as Udoteaceae was downgraded to tribe. Ultimately, whether one prefers Udoteaceae or Udoteae should not jeopardize the following proposed taxonomic revision of the genera.

\subsection{Morphological evolution}

Through phylogenetic signal and correlation analyses, as well as the inference of morpho-anatomical trait evolution on phylogenies, seven characters appeared as the most relevant for taxonomic purposes as well as for the macroevolutionary models 
they represent. These characters (and their most relevant states) are: the frond shape (particularly the "flabellate”, "capitate” and "caespitose” states) (Fig.3. A.), the thallus cortication (particularly the "total thallus cortication" state) (Fig. 3. B), the presence or absence of calcification (both states) (Fig. 3. C), the presence or absence of stipe (both states), the presence or absence of pores on calcified siphons sheath (both states), the secondary structures on frond siphons (particularly the “appendages” state) (Fig. 3. D) and, finally, the type of supra-dichotomial constrictions (the "symmetrical” and “asymmetrical” states).

In the following sections, we use these characters and other results of our study to discuss various hypotheses about the evolution of the family Udoteaceae.

4.2.1 What did the Udoteaceae ancestor look like? According to our results (cf. Data S5), the Udoteaceae ancestor may have had a creeping axis with a multisiphonous non-ramified stipe and a single pluristromatic flabellate frond (Fig. 3. A), all continuously joined together. It may have been entirely corticated (stipe and frond) (Fig. 3. B) and calcified (Fig. 3. C), but the siphons' sheath may have been nonporous. The siphons' ramifications may have been dichotomous and arranged in a single plan, with unaligned isomorphic dichotomies and asymmetric supradichotomial constrictions. Frond and stipe siphons may have been parallel to subparallel and may have had appendages (Fig. 3. D). We estimated the average diameters of the frond and stipe siphons to be $95 \mu \mathrm{m}$ and $70 \mu \mathrm{m}$, respectively. We have no precise estimation for the attachment system.

This ancestral morphology is close to the description of the fossil genus Pseudoudotea (calcified, flabellate frond and siphons with “finger-like” appendages at the margin) 
described by Dragastan et al. (1997). Pseudoudotea belongs to the family Pseudoudoteaceae, with other fossil genera such as Hydra or Garwoodia. Missing information, such as the attachment system or stipe morphology, makes a thorough comparison of their morphology with that of the putative Udoteaceae ancestor impossible, but our results suggest that the morphological characters shared by Pseudoudotea and the putative Udoteaceae ancestor could be the inheritance of a common ancestor between the two families.

Dragastan et al. (1997) proposed to consider the fossil Pseudopenicillus aegaeicus as representative of the former family Udoteaceae. The external morphology of the fossil is similar to the extant genus Penicillus, with a stipe whose siphons bear dichotomously branched "secondary siphons” (appendages) and a capitulum with free siphons. Although the age of the fossil (Early Triassic) coincides with the temporal origin of the putative Udoteaceae ancestor, most of the fossil's morphological characters differ from those inferred for the putative Udoteaceae ancestor. Based on these observations, we believe that Pseudopenicillus represents an extinct genus of family Udoteaceae and does not represent the most recent common ancestor of the entire family.

\subsubsection{Is the modern form inherited from a simple or a complex morphology?}

Various hypotheses have been put forward regarding the morphology of the most recent Udoteaceae ancestor. Some authors argue for a simple, filamentous and uniaxial primitive form (Hillis-Colinvaux, 1984, Meinesz, 1980) or an uncorticated frond (Littler \& Littler, 1999; Dragastan et al., 1997) from which genera with more complex morphologies may have evolved through successive acquisitions of derived states. Others prefer a complex ancestral form from which simpler forms may have 
emerged through successive secondary losses of character states (Kooistra, 2002; Verbruggen et al., 2009b). Our results tend to support the second hypothesis, where the common ancestor to all Udoteaceae species may have had a complex morphology, including the presence of a stipe, and a thallus calcified and corticated throughout (i.e., appendages on both the frond and stipe siphons). The simpler forms may represent derived states, which appeared several times throughout the evolutionary history of the family; i.e., these simpler morphologies represent innovations or ecological adaptations rather than reversions towards a more ancestral state.

This is well illustrated by the morphological character "cortication”, which is often seen as a complex feature but is also very relevant for the taxonomic classification of Udoteaceae. Cortication can be restricted to the stipe or present throughout the thallus (i.e., also on the frond). For Kooistra (2002), total cortication may be ancestral because it occurs in basal lineages (e.g., Flabellia petiolata or Udotea flabellum) and could even predate the Udoteaceae ancestor. For this author, total thallus cortication could correspond to an undifferentiated (stipe and frond similarly corticated) and "primitive" state. In contrast, the presence of cortication in the stipe only may be the differentiated and derived state. This hypothesis contrasts with that of other authors who consider total thallus cortication to be a more evolved and complex state derived from a primitive uncorticated state (Littler \& Littler, 1990a). In our study, the characters related to cortication and types of secondary structures (in stipe or frond) all show strong phylogenetic signals, but the total thallus cortication of the ancestor appears poorly represented within the family (Fig. 3. B). Indeed, our results indicate that the loss of frond cortication occurred several times independently during the evolutionary history of the family and could represent convergent homoplasic 
evolution. This character state was maintained throughout subsequent speciation events and, although more recent evolution towards incomplete cortication is seen for some species (e.g., in Ventalia gen. nov, Fig. 3. B), no reversion to total cortication was observed from an uncorticated state.

The shape of the frond is also an important character, which has often been discussed when considering the morphological complexity of Udoteaceae. Because the flabellate frond is the most common character among the current Udoteaceae genera, Vroom et al. (1998) considered that the hypothesis of an ancestor with a flabellate frond was more parsimonious than the hypothesis of multiple independent appearances of flabellate fronds proposed by Hillis-Colinvaux (1984). Vroom et al. (1998) proposed that the ancestral frond morphology may be a single flabellate frond, like those of Udotea. This early frond may have evolved successively into three different forms: (i) the multiple flabellate fronds arising from a single axis of Rhipocephalus, (ii) a deconstruction of the flabellate frond into free siphon fronds seen in Penicillus, and finally in a last evolutionary jump (iii) the segmented morphology of Tydemania. Our results indicate that the ancestral state (or plesiomorphy) may have been a flabellate frond, and although it is found in most genera, this character state is important for differentiating them (Fig. 3. A). The free siphons frond shape appeared several times as a derived state but led to different forms simultaneously and not successively as proposed by Vroom et al. (1998). In addition, while the capitulum form is homoplasic, the caespitose form or the form with multiple structures (glomeruli/flabella) arising from a single axis are taxonomically informative and synapomorphic for genera (Fig. 3. A). Overall, the evolution from a flabellate form to a free siphon form requires further analyses before it is confirmed or refuted. In addition, these evolutionary 
scenarios will need to be further studied to determine whether it is the result of environmental adaptations (changes in environmental conditions, colonization of new ecological niches), or whether it corresponds to an evolutionary advantage favored by selection.

The loss of character states previously considered as derived and complex (e.g., presence of a stipe, calcification and cortication) appear to be frequent and progressive events throughout the Udoteaceae evolutionary history. Forms considered "simple", such as Chlorodesmis, may be extreme cases of secondary loss of complex character states. Indeed, studies have argued that the very simple morphology of Chlorodesmis could be a case of regression to a simple primitive ancestral state or, a case of neoteny for which the non-calcified "juvenile" stages may have become fertile (Meinesz, 1980; Kooistra, 2002).Genomic efforts combined with transcriptomics could be used to explore the genes involved in morphogenesis. The observation of reproductive structures in some Chlorodesmis species (Gepp \& Gepp, 1911; Ducker, 1965, 1967) has shown that they are fertile forms and not filamentous life stages of more complex and unknown species.

4.2.3 Could the Udoteaceae ancestor have been calcified? Calcification is another diagnostic character for distinguishing between Udoteaceae genera. Our results show that the putative Udoteaceae ancestor may have been calcified and that this character state remained as a symplesiomorphy among most of the extant genera and species (Fig. 3. C). Calcification loss occurred several times independently in the family's evolutionary history. It appears as a homoplasic derived state (parallel evolution) in a few genera including Chlorodesmis s.s, Rhipidodesmis and Flabellia. This result is in agreement with several published hypotheses (Kooistra, 2002; Curtis et al., 2008;

This article is protected by copyright. All rights reserved. 
Verbruggen et al., 2009b). However, other studies have proposed that the Bryopsidales ancestor was uncalcified. Calcification may then have been a derived state resulting from two independent evolutionary events, in the suborders Halimedineae (to which Udoteaceae belongs) and Bryopsidineae (Pedobesia) (Lam \& Zechman, 2006; Verbruggen et al., 2009b). A broader phylogenetic analysis and reconstruction of ancestral character states, including the Halimedineae suborder or other members of the Bryopsidales, is needed to assess if calcification is a plesiomorphy (as for Udoteaceae) and if the absence of cortication is an homoplasic derived state or a reversion to an older ancestral state (e.g., Bryopsidales ancestor).

Because it makes algae less palatable and the whole thallus stronger, particularly the siphon's structures, calcification was considered as an ecological advantage against herbivores (Hay et al., 1994, Littler \& Littler, 1990a) or when facing physical environmental pressures (Littler \& Littler, 1990a). The occurrence of calcified and non-calcified Udoteaceae taxa was also linked to environmental conditions, especially the concentration and type of environmental organic matter, which is likely to influence algal metabolism through $\mathrm{CaCO}_{3}$ precipitation (Kooistra, 2002). This could explain the seasonal and alternate occurrence of calcified and non-calcified forms of Penicillus capitatus in the Mediterranean (non-calcified form: P. capitatus f. mediterraneus ex- "Espera") (Meinesz, 1980). However, the occurrence of both calcified and non-calcified taxa within the same habitat (e.g., Geep \& Gepp (1911), Farghaly (1980), Littler \& Littler (2000), Coppejans et al. (2001), etc.) indicates that calcification does not only depend on the environment. Culture experiments are needed to explore the link between calcification and environmental conditions. 
Finally, our results highlight the correlation between calcification and the presence of a stipe (Fig. 3. C, Data S5, Table S11). This corroborates observations made in some species whose calcified forms have a stipe while the filamentous and non-calcified forms have none (e.g., see the work on Penicillus by Friedman \& Roth (1977) or Meinesz $(1972,1975,1980))$. The presence of a stipe is known to be related to the type of anchoring substrate. Species with a stipe are most often encountered in soft substrates, where calcification could help to remain erect from substrate. Soft substrates are usually found in open environments exposed to grazing, where calcification could also represent a defense strategy (even if the grazing pressure is lower than in the reef environment).

\subsubsection{Are pores and appendages functional traits? The "window" function was} introduced by Gepp \& Gepp (1911) for pores visible on the calcified surface of siphons or the secondary structures on siphons. These two structures are believed to promote and increase contact with the surrounding environment and facilitate the flow of nutrients and light inside the siphon. Like Littler \& Littler (1990a), we observed that species with appendages or protuberances do not have pores on the surface of siphons (e.g., species of Udotea s.s. and Ventalia gen. nov.). In contrast, pores are present in calcified species with naked siphons (e.g., species of Penicillus or Rhipidosiphon s.s.). Additionally, our correlation tests confirmed that the presence and absence of pores and the secondary structures of the frond siphons are two correlated characters (Table S11). Similarly, ancestral reconstructions have shown that, in most cases, these characters are linked to evolutionary processes (pores appear when appendages are lost) (Fig. 3. D and Data S5). However, some calcified species of Ventalia gen. nov. do not have secondary structures or pores. The combination of 
low calcification and very thin frond could explain why particular structures, such as pores and appendages which facilitate exchanges with the environment, are not necessary (N.B.: Although the genus Rhipidosiphon s.s. is monostromatic, the strong frond calcification could explain the presence of pores on the siphons surface).

Our analysis also revealed that the presence or absence of pores and secondary structures (or cortication) on the siphons were correlated (among others) to the shape and thickness of the frond or to the diameter and arrangement of siphons (in one or several planes) (Table S11). This result corroborates the notion of “windows” (Gepp \& Gepp, 1911) and their function for the continuity of exchanges between the surrounding environment and the inside of the siphon. In conclusion, the presence of pores on the calcified surface of the siphons, which represents a parallel homoplasic evolution (Data S5), may correspond to a functional homoplasy. In contrast, the presence of appendages, which represents a symplesiomorphy (Data S5), may be a functional plesiomorphy.

\subsubsection{Are constriction type indicator of generic boundaries? The type of dichotomy} constrictions also had a strong phylogenetic signal, and ancestral reconstruction highlighted it as an important diagnostic character at the genus level (Data S5). The only exception is the genus Chlorodesmis s.s., which has species with various types of dichotomy constrictions. Gepp \& Gepp (1991) and Littler \& Littler (1990a) discussed the distinct geographical patterns of this trait in Udotea species of the Caribbean and Indo-Pacific regions. However, this pattern was less evident in our study. We found that all Caribbean taxa have symmetrical constrictions, except Udotea s.s. species, while Indo-Pacific species of Udotea s.s., Glaukea gen. nov. and Ventalia gen. nov have asymmetrical constrictions above the dichotomies. Despite its high phylogenetic 
signal, the evolution and geographical distribution of this character state remains difficult to explain.

For Farghaly (1980), this character is of no taxonomical importance because whether the constrictions are "aligned" or "mismatched" (i.e., symmetrical or asymmetrical, respectively) accounts for the regular or irregular siphon growth rates, respectively. From our observations, we believe the constrictions appear long after the branches are fully grown, and this is why apical dichotomies (on the siphons margin) generally do not have constrictions yet.

Functionally, the constrictions help to limit the loss of cytoplasm during grazing by herbivores by allowing rapid occlusion of the siphons (Duffy \& Hay, 1990; Menzel et al., 1998; Vroom et al., 2001). As Udoteaceae species are found in environments with different grazing pressures, the arrangement of constrictions (on one or two levels) may be the result of various evolutionary adaptations to specific environments.

\subsection{Systematics revisions and taxonomic treatment}

In this section, we discuss the revised clades (as delimited in Figure 1.B) individually, based on both the molecular (species delimitation and phylogeny) and morphological (observations and phylogenetic inference of character) results. We include details about the proposed systematic and taxonomic revisions, species diversity, geographical distribution and diagnostic morphological characters. The genera Tydemania (Clade A) and Flabellia are not detailed here, as no taxonomic changes have been applied to them (but see Lagourgue et al. (2019) for more details about the morphology, diversity and distribution of Tydemania species).

This article is protected by copyright. All rights reserved. 


\subsubsection{Udotea sensu stricto (Udotea group 1- Clade B)}

Clade B is strongly supported (bs: 97; PP: 0.98) and contains six Udotea species, including the type-species U. flabellum (J. Ellis \& Sollander) M. Howe, and therefore represent Udotea s.s. It is composed of species found in the Caribbean (U. dixonii, $U$. dotyi, U. occidentalis) and the Pacific (U. geppiorum, U. sp1) (Figure 4). Udotea is strongly calcified and characterized by a stubby thallus with a pluristromatic flabellate frond. The frond can be lobed and entire or divided or segmented, with segments inserted in each other in a ‘tongue and groove’ arrangement (Sauvage et al., 2020). The rhizoidal system is well-developed and bulbous. The frond siphons have welldeveloped secondary structures called appendages. These latter are either dichotomously divided or lobed, and all have numerous well-defined apices. The cortication is complete, i.e., appendages are present throughout the stipe and the frond. The specific symplesiomorphies and synapomorphies of the Udotea genus are shown in Figure 4.

Considering these species as part of distinct lineage is not entirely new but had never been formalized nor verified molecularly. Previous authors proposed to consider some of these species in a proper group, named in turns "corticatae" (Agardh, 1887; $U$. flabellum only), an unnamed group by Gepp \& Gepp (1911; U. flabellum, U. argentea, $U$. occidentalis, $U$. verticillosa and $U$. wilsonii), “completely corticated blade” (Nizamuddin, 1963), “Udotea” (Farghaly, 1980; U. flabellum, U. argentea and U. occidentalis), "Flabellum” (Littler \& Littler, 1990a; including only the Caribbean species $U$. flabellum, $U$. dixonii, $U$. dotyi, $U$. occidentalis and $U$. norrisii), and “complete corticated species” (Dragastan et al., 1997; U. flabellum). 
Futhermore, Tseng \& Dong (1975) described several Udotea species from China. Despite very brief descriptions, they mention species with long and dichotomously ramified lateral branches on siphons, which could refer to appendages, and could correspond to Udotea s.s. species (U. reniformis, U. tenax, U. tenuifolia, U. velutina and $U$. xishaensis). Nevertheless, morphological and molecular verification is needed for confirmation.

Species of the genus Udotea s.s. are characterized by limited morphological variations compared to other ex-Udotea species, as previously noticed by Kooistra (2002), who considered this lineage to be ancestral. Results of our time-calibrated phylogeny confirmed that Udotea s.s. was indeed one of the oldest genera to diverge in the family (ca 109 Ma, $c f$. Figure 2). This morphological resemblance between the species in situ could explain several erroneous identifications that have led to an overestimation of their distribution range. The genus has a wide geographical repartition, but the distribution range of species is more restricted than previously reported. For example, $U$. flabellum does not occur worldwide, but appears limited to the western tropical Atlantic (Figure 4). Similarly, we found that the Atlantic species, U. occidentalis, has a sister species in the Pacific, $U$. sp1 (bs: 100; PP: 1), which is close morphologically (lobed aspect of the frond appendages and similar siphon diameter but different stipe appendages).

Udotea J. V. Lamouroux

Diagnosis: Lamouroux JVF. 1812. Sur la classification des polypiers coralligènes non entièrement pierreux. Nouveaux Bulletin des Sciences, Societé philomatiques de Paris 3: $181-188$.

This article is protected by copyright. All rights reserved. 
Type species: $U$. flabellum (J. Ellis \& Solander) M. Howe; Type: unknown; Type locality: West Indies, Basionym: Corallina flabellum, Ellis \& Solander; Synonyms: Udotea flabella J.V. Lamouroux; Udotea halimeda Kützing

List of species (as per this study): U. flabellum, U. occidentalis, U. geppiorum, $U$. dotyi, $U$. dixonii, and $U$. sp1 (new species to be described).

\section{Morphological description emended from Lamouroux (1812) and Gepp \& Gepp}

(1911)): Flabellate, pluristromatic, corticated and highly calcified frond;

Multisiphonous, corticated and calcified stipe; Continuous stipe-frond junction;

Bulbous holdfast and well-developed rhizoidal system; Frond and stipe siphons with appendages, either dichotomously divided or lobed, with numerous well-defined apices; Siphons dichotomously branched; Dichotomies isomorphic and not aligned; Asymmetrical supra-dichotomial constriction; Non-porous siphons sheath.

\section{Geographic distribution (confirmed using DNA sequencing): Atlantic Ocean:}

Caribbean Is. (Lagourgue et al., 2018; This study), Mexico (Lam and Zechman, 2006), Bermuda (Lagourgue et al., 2018), Florida (Lagourgue et al., 2018), Bahamas (Lagourgue et al., 2018), Honduras (Kooistra, 2002), Panama (Kooistra, 2002;

Kooistra et al., 2002; Lagourgue et al., 2018), Jamaica (Lagourgue et al., 2018);

Pacific Ocean: Hawai`i (Sauvage et al., 2016), Papua New Guinea (This study); Solomon (This study), Tonga, Fiji (Sauvage et al., 2019; This study), New Caledonia (Grande Terre, Surprises Is., Chesterfield Is.) (This study).

\subsubsection{Glaukea gen. nov. (Udotea group 2 - Clade C)}

The new genus Glaukea (bs: 100; PP: 1, Fig. 1) is proposed to accommodate specimens previously assigned to Udotea argenta Zanardini (Figure 1). The genus 
Glaukea is characterized by a flabellate and zonate frond, entire or more or less divided, siphons with diameter $<80 \mu \mathrm{m}$ and lobed appendages with rounded, swollen and convex apices (Figure 5). Our results indicate that the genus is composed of two genetically distinct species (bs: 100; PP: 1 for both; Fig. 1) that both match the very brief original diagnosis of $U$. argentea (Zanardini, 1858). However, we were unable to confirm the identity of the two species for two reasons: 1) we have no specimen from the type locality (Suez, Egypt); and 2) we could not locate the type specimen. The resolution of this case requires observations of the type specimen and the sequencing of samples from the type locality for lectotypification. This new genus is thus a complex of species that we refer to as Glaukea argentea 1 and G. argentea 2 until further study provides clarification to confirm species name. In any case, this clade can no longer be considered as Udotea in the present assessment, considering the topology of the tree.

The genus Glaukea has retained several ancestral states and has many symplesiomorphies including a flabellate pluristromatic frond, a plurisiphonous stipe that is not ramified, with a continuous stipe-frond junction, calcified siphons sheath without pores, thallus cortication, complete cortication of the frond and stipe, dichotomously ramified siphons that are arranged in one plan, and parallel to subparallel in the frond, random and isomorphic dichotomies, with asymmetrical supra-dichotomial constrictions, and appendages on frond and stipe siphons. Two synapomorphies were also highlighted including a bulbous holdfast and the presence of an erect axis. The current distribution of the genus is Indo-Pacific, with G. argentea 1 distributed throughout the area while G. argentea 2 seems restricted to Madagascar.

Glaukea Lagourgue \& Payri gen. nov.

This article is protected by copyright. All rights reserved. 
Type species: Glaukea argentea (Zanardini) Lagourgue \& Payri comb. nov.; Type: unknown; Type locality: Suez, Egypt; Basionym: Udotea argentea Zanardini, J. 1858. Plantarum in mari Rubro hucusque collectarum enumerato (juvante A. Figari). Memoirie del Reale Istituto Veneto di Scienze, Lettere ed Arti 7: 209-309, pls III-XIV.

List of species (as per this study): Glaukea argentea, G. sp1. Comment: Since the type specimen is unknown and no specimen of type locality could be sequenced, further studies are needed to clarify the taxonomic status of the two Glaukea taxa.

Etymology: from the Greek "glaukos" meaning a green color with a blue tinge, in connection with the color of the thallus in situ.

\section{Morphological description emended from Zanardini (1858) and Gepp \& Gepp}

(1911): Flabellate, sub-reniform to lobed frond, more or less cut out, striated, zonate and pluristromatic, entire or eroded upper margin, pale green-grey to ashy green; Short and not-ramified stipe, plurisiphonous, with a continuous stipe-frond junction; Bulbous holdfast; The thallus is calcified with non-porous siphon sheath; Siphons ramify in dichotomy and are arranged in one plan, parallel to subparallel in the frond; The dichotomies are not aligned and isomorphic with asymmetrical supra-dichotomial constrictions; Siphons diameter $<80 \mu \mathrm{m}$ with decreasing size towards the apex in the blade and 25-100 $\mu \mathrm{m}$ in the stipe; Total cortication of the thallus through the presence of appendages on siphons; In the frond, siphons have numerous pyriform and lobed appendages (100-200 $\mu \mathrm{m}$ long), alternately or distically arranged, constricted at the base and with rounded, swollen and convex apices; In the stipe, siphons appendages (300 -800 $\mu \mathrm{m}$ long) are dischotomously ramified (1-4 times) and digitate ("fingerlike”) and with obtuse or swollen apices. 
Geographical distribution (confirmed using DNA sequencing): Indian Ocean: Mayotte (This study), Scattered Islands (Glorioso Is., Juan de Nova Is.) (This study), Madagascar (This study); Pacific Ocean: Guam (Kooistra, 2002), Papua New Guinea (Cremen et al., 2019; This study). For more detailed distributions in Indo-Pacific and Red Sea, see Guiry \& Guiry (2020). However, others distribution reported by solely morpho-anatomical data (Guiry \& Guiry, 2020) need further verification by DNA sequencing, due to potential confusion with some Udotea species (e.g., U. flabellum, U. geppiorum).

\subsubsection{Chlorodesmis sensu stricto (Clade D)}

Based on our results, we propose to circumscribe the genus Chlorodesmis s.s. to the clade containing the type species $C$. fastigiata (bs: 92; PP: 0.8). This clade includes five other species, three of which are probably new (C. sp2, C. sp3, C. sp5), while the identification of the two others requires further verification (C. cf. hildebrandtii and $C$. cf. major, Figure 6). We exclude the species C. caespitosa, which was recovered in Clade I, and C. baculifera, which grouped outside of the family Udoteaceae (preliminary analyses, publication in prep). Molecular analyses of the Chlorodesmis species not included in our study (C. papenfussii, $C$. dotyi, C. haterumana, C. mexicana and C. sinensis) are needed to confirm their status, particularly since their morphological descriptions are relatively short (Taylor, 1945; Trono, 1971; Itono, 1973; Tseng \& Dong, 1978), which makes it impossible to discuss their possible status.

The genus Chlorodesmis is characterized by an uncalcified thallus in tufts, composed of a discoid base from which arise free and interwoven siphons dichotomously divided and constricted. The symplesiomorphies and synapomorphies characterizing the genus and shown in Figure 6, are useful for distinguishing the genus from other filamentous species, particularly the caespitose tufted blade, the absence of cortication or the presence of supra-

This article is protected by copyright. All rights reserved. 
dichotomial constrictions. Indeed, due to their relatively simple morphology, there are only few diagnostic characters available to identify Chlorodesmis species, and this has most likely led to misidentifications in the past. Many non-calcified and tufted filamentous forms belonging to other lineages and families could have been confused with Chlorodesmis and reassessing these records, using the diagnostic characters highlighted here, could reveal very different geographical distribution patterns.

Overall, our study confirms that the genus does not occur in the Atlantic Ocean, and its geographical distribution extends throughout the Indo-Pacific. Some of the species have wide geographic distribution (e.g., C. fastigiata and C. sp5), while others appear more restricted (e.g., C. sp2 and C. sp5 in the WIO region) (Figure 6).

Chlorodesmis Harvey \& Bailey

Diagnosis: Harvey WH, Bailey JW. 1851. Description of seventeen new species of algae, collected by the United States Exploring Expedition. Proc. Boston Soc. Nat. Sci. 3: 370-373.

Type species $=$ Chlorodesmis fastigiata $($ C. Agardh) S.C. Ducker; Type: LD \#15661, Herb. Alg. Agardh (LD); Type Locality: Mariannes Is. (Micronesia); Basionym: Vaucheria fastigiata C. Agardh - Synonyms: C. comosa Harvey \& Bailey; Avrainvillea comosa (Harvey \& Bailey) G. Murray \& Boodle.

List of species (as per this study): C. fastigiata, $C$. cf. hildebrandtii, $C$. cf. major and three new species to be described (C. sp2, C. sp3 and C. sp5).

\section{Morphological description emended from Harvey \& Bailey (1851) and Gepp \&}

Gepp (1911): Uncalcified thallus with a felted, spongious, colorless and discoid base, bearing a green tuft of free and interwoven siphons; Siphons cylindrical, 
dichotomously branched and with numerous constrictions ("pseudo-articulated" in original diagnose of Harvey \& Bailey); Round or pointed apices; Dichotomies iso- or anisomorphic; Symmetrical or asymmetrical supra-dichotomous constrictions with ring of cell-wall for most of species.

\section{Geographical distribution (confirmed using DNA sequencing): Indian Ocean:} Mayotte (This study), Scattered Is. (Glorioso Is, Juan de Nova Is.) (This study), Madagascar (This study), Maldive Is. (This study); Pacific Ocean: Okinawa (Japan) (Sauvage et al., 2016), Guam (Verbruggen \& Schils, 2012), Papua New Guinea (This study), Australia (Lizard Is.) (Kooistra, 2002), New Caledonia (Grande Terre, Surprises Is.) (This study), French Polynesia (Verbruggen et al., 2009b; This study).

\subsubsection{Ventalia gen. nov. (Udotea group 3 - Clade E)}

The new genus Ventalia is proposed to accommodate species of clade E (bs: 93; PP: 1, Fig. 7) formerly known as Udotea orientalis, U. indica and U. papillosa, as well as four additional taxa ( $V . \mathrm{sp} 1, V . \mathrm{sp} 2, V . \mathrm{sp} 3$ and $V . \mathrm{sp} 4)$ which may represent new species (Figure 7). Each of these new species are highly supported (bs: 100; PP: 1, Fig. 7), except Ventalia sp2. Ventalia has a flabellate mono or pluristromatic frond, uncorticated (naked siphons lacking secondary structures) or pseudo-corticated siphons (i.e., with rounded or spinous protuberances all around or only on the external and exposed side of the siphon) (Figure 8). The rhizoidal system is limited. The stipe is mono- or plurisiphonous, corticated or pseudo-corticated, partially or fully calcified. In plurisiphonous stipes, siphons have appendages of various aspects ranging from simple swellings to more developed structures dichotoumously divided, or with terminal dichotomies only in stubby appendages (Figure 8). The siphons are thin $(<45$ 
$\mu \mathrm{m}$ in diameter) with a porous surface and the dichotomies have asymmetrical constrictions (see Figure 7 for detailed symplesiomorphies and synapomorphies). These species are very similar morphologically and are difficult to distinguish without a thorough anatomical analysis. This is particularly true for the cryptic species without protuberances (i.e., naked siphons; V. orientalis, $V$. sp3 and V. sp2), which would not be distinguished from each other without detailed anatomical or molecular analyses.

A similar grouping was informally proposed by several authors: Agardh (1887) subdivided species according to the stipe cortication and included $U$. orientalis in a “Palmattae” group; Nizammudin (1963) created a group for species with partially corticated frond and pointed apices; Farghaly (1980) grouped U. indica, U. palmetta and U. papillosa but not $U$. orientalis in a lineage called "Decaisnella” (invalid name); Finally, Gepp \& Gepp (1911) considered U. indica, U. palmetta, U. papillosa and U. orientalis as part of a same group without naming it.

Although we included no sample of $U$. palmetta in our study, we believe that its morphology, as described in other studies (Decaisne, 1842; Gepp \& Gepp, 1911; Farghaly, 1980) could match this new genus. Tseng \& Dong (1975) also described two Udotea species from China (Udotea fragifolia and U. renuifolia). Despite very brief descriptions, they mention species with simple lateral branches on siphons, which could refer to protuberances, a diagnostic character of several Ventalia species. Morphological and molecular studies of these species are needed to confirm their transfer to Ventalia.

The geographical distribution of the genus is Indo-Pacific. The species are restricted either to the Indian Ocean (V. papillosa, $V$. indica but also $V$. sp2 only found in 
Madagascar) or to the Pacific Ocean (V. sp1 and V. sp4) (Figure 7). Although $U$. orientalis is recorded throughout the Indo-Pacific (Guiry \& Guiry, 2020), we were only able to include Western Indian Ocean (WIO) specimens in our study. Given the possible misidentifications of the other records, further analyses of $V$. orientalis specimens from the rest of its distribution range are needed.

Ventalia Lagourgue \& Payri gen. nov

Type species: Ventalia indica (A.Gepp \& E.S.Gepp) Lagourgue \& Payri comb. nov.

List of species (as per this study): The genus is composed of seven species: $V$. orientalis, $V$. indica, $V$. papillosa and four new species to be described ( $V . \mathrm{sp} 1, V$. sp2, $V . \operatorname{sp} 3$ and $V . \operatorname{sp} 4)$.

Etymology: from the Greek "ventália”, with regard to the flabellate (fan-shaped) frond

Morphological description: Flabellate frond, mono or pluristromatic, uncorticated or pseudo-corticated, calcified without porous siphons sheath; Stipe mono- or plurisiphonous, corticated or pseudo-corticated, partially or fully calcified; Stipe-frond junction continuous; Reduced rhizoidal system reduced; Frond siphons parallel to subparallels, naked or with protuberances; diameter $<45 \mu \mathrm{m}$; Siphon ramification by dichotomies, not aligned; Asymmetrical constrictions above dichotomies; Stipe siphons with appendages and/or ascending laterals.

Geographic distribution (confirmed using DNA sequencing): Indian Ocean: Scattered Islands (Glorioso Is., Juan de Nova Is.) (This study), Madagascar (This 
study); Pacific Ocean: Hawai‘i (Wade \& Sherwood, 2017), Papua New Guinea (This study), New Caledonia (Grande Terre, Chesterfield Is., Surprises Is.) (This study).

Ventalia indica (A.Gepp \& E.S.Gepp) Lagourgue \& Payri comb. nov.

Type: holotype: J. A. Murray in Herb. Mus. Brit.; BM000515946

Basionym: Udotea indica A.Gepp \& E.S. Gepp, 1911. The codiaceae of the Siboga Expedition, including a monograph of Flabellarieae and Udoteaceae. Siboga-Expeditie 62: $1-150$.

Type locality: Karachi, Pakistan

Ethymology: pertaining to India (Latin adjective)

Morphological description: see Gepp \& Gepp (1911).

Geographic distribution (confirmed using DNA sequencing): Indian Ocean: Madagascar (This study). Guiry \& Guiry (2020) report an Indo-Pacific distribution, but we did not find $U$. indica specimen in the Pacific, and that should thus be genetically confirmed.

List of vouchers from this study: Madagascar, Nosy Hao, 2016: NOU203645, NOU203653.

Comment: $U$. orientalis is the most widespread species, but its type could not be located. Instead, we have chosen $U$. indica to represent the type species of Ventalia because its type specimen is correctly listed and deposited in BM.

Other species needing new combinations:

This article is protected by copyright. All rights reserved. 
Ventalia orientalis (A.Gepp \& E.S.Gepp) Lagourgue \& Payri comb. nov.

Basionym: Udotea orientalis A.Gepp \& E.S. Gepp, 1911. The codiaceae of the Siboga Expedition, including a monograph of Flabellarieae and Udoteaceae. SibogaExpeditie 62: 1-150.

Synonym: Rhipidosiphon orientalis (Gepp \& Gepp) Farghaly

Type: ${ }^{\circ}{ }^{\circ}$ 261, 262, 263 (Siboga Expedition: Stat. 64. Island Tanah-Djampeah, 30 m.); Hildebrandt, $\mathrm{n}^{\circ} 1918$ (Lamu Harbour, Zanzibar coast, covered at low water) Note that none of these specimens could be located in a referenced Herbarium.

Type locality: syntypes localities - various in Indian and Pacific Oceans; Indonesia; Philippine Islands

Ethymology: eastern (Latin adjective)

Morphological description: see Gepp \& Gepp (1911).

Geographical distribution (confirmed using DNA sequencing): Indian Ocean: Madagascar (This study). Ventalia orientalis is recorded throughout the Indo-Pacific (Guiry \& Guiry, 2020 as Udotea orientalis), but only specimens from the Indian Ocean have been genetically verified. A molecular verification of specimens recorded in the Pacific Ocean is required.

List of vouchers from this study (limited to 2 per locality): Madagascar, Nosy Mitsio, 2016: NOU203674, NOU203676; Madagascar, Nosy Lava, 2016: NOU203678, NOU203680; Madagascar, Radama, 2016: NOU203703, NOU203722; 
Madagascar, Nosy Sakatia, 2016: NOU203737; Madagascar, Nosy Manitsa, 2010: PC0171887; Madagascar, Baravo Lagoon, 2010: PC0142723.

Ventalia papillosa (A.Gepp \& E.S.Gepp) Lagourgue \& Payri comb. nov.

Basionym: Udotea papillosa A. Gepp \& E.S. Gepp, 1911. The codiaceae of the Siboga Expedition, including a monograph of Flabellarieae and Udoteaceae. SibogaExpeditie 62: 1-150.

Synonym: Decaisnella papillosa (Gepp \& Gepp) Farghaly

Type: unknown

Type locality: syntype localities - various in Indonesia, including Noimini Bay (Teluk Noilmina), Timor.

Ethymology: papillate, covered with papillae (Latin adjective)

Morphological description: see Gepp \& Gepp (1911) for the description of the species.

Geographical distribution (confirmed using DNA sequencing): Indian Ocean: Scattered Islands (Glorioso Is.) (This study), Madagascar (This study).

List of vouchers from this study (limited to 2 per locality): Madagascar, Sainte Marie Is., 2016: NOU203581, NOU203595; Madagascar, Cap Masoala, 2016: NOU203602, NOU203603; Scattered Islands, Glorioso Is., 2012: NOU087254 


\subsubsection{Rhipidosiphon sensu stricto (Clade F)}

Clade F is well supported in the BI phylogeny (PP: 0.99; bs: 53) and includes the type-species $R$. javensis, which led us to consider the clade as representative of Rhipidosiphon s.s. It also includes five Rhipidosiphon taxa, two of which possibly correspond to new species (Figure 9). According to our species delimitation analysis (Fig.S1 \& S2 SI), and morpho-anatomical data (when available), it is likely that $R$. sp2 (SSH34), R. sp3 (SSH 32), R. sp5 (SSH 55), R. sp 6 (SSH 56), R. sp8 (SSH 60) R. sp9 (SSH 61), and Udotea sp10 (SSH62) belong to Rhipidosiphon s.s. However, missing molecular data prevented us from including them in the multilocus analysis.

The genus Rhipidosiphon s.s. is characterized by an uncorticated monostromatic flabellate frond, a stipe, which is monostromatic at the base and, in some instances, becomes plurisiphonous near the frond. The stipe is pseudo or fully uncorticated and partially calcified or fully uncalcified. A detailed list of symplesiomorphies and synapomorphies characterizing the genus Rhipidosiphon is shown in Figure 9. Based on our morphological and molecular results (Figures 9, S1 \& S2), we propose to transfer the species Udotea glaucescens to this genus. This was previously suggested by Nizammudin (1963) and Farghaly (1980) but not validated (Guiry \& Guiry, 2020). On the other hand, because it clustered in clade $\mathrm{H}$, we propose to exclude $R$. floridensis from Rhipidosiphon s.s.

We identified the type species, $R$. javensis among our samples collected in Bunaken Island (Sulawesi, Indonesia), which is located near the type locality (Leiden Island, Nyamuk-besar, Java, Indonesia). However, the sequence of our specimen did not match with the $r b c L$ sequences recorded in the Genbank under the same epithet 
(DML40128, DML40134). Due to the strong species crypticity of the genus Rhipidosiphon, we suspect that the specimens corresponding to the Genbank sequences could have been misidentified. Besides, these specimens were collectedfrom the Great Astrolabe Reef in Fiji, which is more distant from the type locality. The geographical distribution of the genus is strictly Indo-Pacific. According to Guiry \& Guiry (2020), the most widespread species is $R$. javensis, for which records are available throughout the Indo-Pacific region. However, it is highly likely that some of these records represent erroneous identifications, such as the example cited above. Therefore, it is possible that the distribution of $R$. javensis is more restricted than previously thought, which is the case for most other species of the genus (e.g., R. glaucescens and R. lewmanomontiae in the south and northwest Pacific, respectively) (Figure 9).

However, according to the results of the individual gene trees (tufA, $r b c L$ and $18 \mathrm{~S}$ rDNA) (see Figures S1, S2 and S4 respectively), where species do not form monophyletic clades, and due to the weak root node support in the ML multilocus tree, the genus Rhipidosiphon, as proposed in this study, remains to be confirmed. We recommend the sequencing of more species, more individuals per species, as well as neighbouring clades.

Rhipidosiphon Littler \& Littler

Diagnosis: Montagne, J.F.C. 1842. Prodromus generum specierumque phycearum novarum, in itinere adpolum antarcticum...collectarum. Paris. 16 pp. 
Type species: $R$. javensis Montagne; Type: PC, coll: Hombron; Type locality: Leiden Island (Nyamik-besar), near Jakarta, Java, Indonesia; Synonym: Udotea javensis (Montagne) A. Gepp \& E.S. Gepp.

List of species (as per this study): $R$. javensis, $R$. lewmanomontiae, $R$. glaucescens comb. nov. and two other new species to be described ( $R$. sp1 and $R$. sp4).

\section{Morphological description emended from Littler \& Littler (1990) and Gepp \&}

Gepp (1911): Flabellate, calcified, monostromatic and uncorticated frond;

Monosiphonous (becoming plurisiphonous near the frond in some species),

uncorticated or pseudo- corticated, partially or not calcified; Stipe-frond junction

continuous; Fine hyaline rhizoids at the base; Frond siphons cylindrical,

dichotomously branched, arranged in parallel to sub-parallel, without anastomosis but cemented by calcification; Isomorphic dichotomies with asymmetrical constrictions above; Porous siphon sheath.

Geographic distribution (confirmed using DNA sequencing): Indian Ocean: Mayotte (This study), Juan de Nova Is. (This study), Madagascar (This study), Maldive Is. (This study); Southeast-Asia: Thailand (Coppejans et al., 2011), Bunaken (This study); Pacific Ocean: Okinawa (Sauvage et al., 2016), Papua New Guinea (This study), Vanuatu (This study), New Caledonia (Grande Terre, Surprises Is.) (This study), Fiji (Coppejans et al., 2011; This study), Tonga (This study).

New combination proposed:

Rhipidosiphon glaucescens (Harvey ex J.Agardh) Lagourgue \& Payri comb.nov. 
Basionym: Udotea glaucescens Harvey ex. J. Agardh (Agardh J.G. 1887. Till Algernes Systematik.Nya bidrag. Acta Universitatis Lundensis 23: 1-174, 5 plates).

Type locality: Tonga

Type: Unknown

Ethymology: becoming glaucous (Latin adjective).

Morphological description: see J. Agardh (1887) and Gepp \& Gepp (1911)

Geographical distribution (confirmed using DNA sequencing): Pacific Ocean: Vanuatu (This study) and Fiji (This study).

List of vouchers from this study: Fiji, Nagelelevu Lagoon, 2007: NOU087262; Fiji, Heemskercq reef, 2007: NOU087250; Fiji, Vanua Levu, 2007: NOU087256; Vanuatu, Bridgestock point, 2006.

\subsubsection{Udoteopsis gen. nov. (Udotea group 4- Clade G)}

The genus Udoteopsis is proposed to accommodate a new species represented by specimens collected in Madagascar and Mayotte (WIO region). The monospecific genus is wellsupported (bs: 100; PP: 1, Fig. 1) but its phylogenetic relationship to the genera Chlorodesmis, Ventalia gen.nov. and Rhipidosiphon is weakly supported (bs: 67; PP: 0.93, Fig. 1). Additional sampling is needed to confirm its phylogenetic relationships within the Udoteaceae (Figure 1). The genus is characterized morphologically by a monostromatic calcified flabellate frond, irregular margins with growth zones where siphons are free (no calcified cement) (Figure 10). The siphons are cylindrical, naked and swollen at the apices. Isolated constrictions between the dichotomies are observed and more numerous in the growth area. The siphons measure $100 \mu \mathrm{m}$ in diameter and decrease in size towards the 
apex $(50-60 \mu \mathrm{m})$. The dichotomies have asymmetric constrictions, and some trichotomies are also observed. The stipe is multisiphonous, entirely calcified and corticated with appendages on the siphons. The stipe siphons are $100 \mu \mathrm{m}$ in diameter for a total stipe width of $500-700 \mu \mathrm{m}$. The calcified surface of the siphons is porous to with cracks (Figure 10). The genus has several symplesiomorphies: a unique flabellate frond, calcification, a plurisiphonous stipe with a continuous stipe-frond junction, dichotomous siphon ramifications, primary siphons arranged in one plane, random and isomorphic dichotomies, asymmetrical constrictions, appendages on the stipe's siphons and complete stipe cortication. Synapomorphies include a monostromatic frond, a reduced rhizoidal system, an erected axis, the presence or absence of supra-dichotomial constrictions and the absence of frond cortication. The new genus is exclusively found in the WIO region and so far, only known from Mayotte and Madagascar.

Udoteopsis Lagourgue \& Payri gen. nov.

Type species: Udoteopsis maiottensis Lagourgue \& Payri sp. nov.

Ethymology: named in reference to the morphological resemblance to the genus Udotea.

Morphological description: Flabellate, monostromatic and calcified frond with irregular margin; Multisiphonous, calcified and corticated stipe (500-700 $\mu \mathrm{m}$ width); Continuous stipe-frond junction; Reduced rhizoidal system; Frond siphons cylindrical and naked siphons branching dichotomously with supra-dichotomous constrictions; Stipe siphons with appendages; Porous siphons sheath.

Geographic distribution (confirmed using DNA sequencing): Western Indian Ocean: to date the genus is only known from Mayotte and Madagascar (This study). 
Udoteopsis maiottensis Lagourgue \& Payri sp. nov.

Types: holotype: NOU203562 (Mayotte, 2016); isotypes: NOU203560, NOU203561, NOU203570, NOU203580 (Mayotte, 2016), NOU204161 (Mayotte, 2010), PC0171655, (Madagascar, 2010)

Type locality: Mayotte; syntype locality: Madagascar

Ethymology: in reference to the species type-locality, Mayotte (Latin Maiotta)

Morphological description: Monostromatic, uncorticated, calcified, flabellate to feather-shaped frond, irregular margin with growth and free siphons (lacking calcification cement); Multisiphonous, corticated and calcified stipe; Stipe width of 500-700 $\mu \mathrm{m}$; Continuous stipe-frond junction; Reduced rhizoidal system; Siphons cylindrical, naked and swollen at the apices in the frond, and highly constricted in growth zone; Siphons with appendages in the stipe; Siphons branching dichotomously; Some trichotomies; Isomorphic and not-aligned dichotomies; Asymmetrical constrictions above dichotomies; Siphons diameter of $100 \mu \mathrm{m}$ (in frond and stipe) decreasing toward the apex (up to 50-60 $\mu \mathrm{m}$ ) in the frond; Siphons surface porous to crack.

Geographical distribution (confirmed using DNA sequencing): Mayotte (This study), Madagascar (This study).

List of vouchers from this study: Mayotte, Tanaraki, 2016: NOU203560, NOU203561, NOU203562; Mayotte, N'gouja, 2016: NOU203570; Mayotte, Surprise Pass, 2016: NOU203580; Mayotte, 2010: NOU204161; Madagascar, Gallions Bey, 2010: PC0171655.

This article is protected by copyright. All rights reserved. 


\subsubsection{The "Penicillus-Rhipidosiphon-Rhipocephalus-Udotea (PRRU) complex"}

(Clade H)

Clade H, which is well supported (bs: 85; PP: 0.96, Fig. S5), includes specimens exclusively collected in the Western Tropical Atlantic (mostly in the Caribbean) and representing species only found in this region except for Penicillus capitatus, which distribution would also extend to the Mediterranean Sea (Meinesz, 1972 and 1975; see Guiry \& Guiry, 2020 for more references) but this has to be confirmed genetically. Morphologically, all these species correspond to distinct and polyphyletic genera (Udotea, Penicillus, Rhipidosiphon, Rhipocephalus) (Figure S5), which results in high morphological diversity and discontinuities within this clade.

Few symplesiomorphies and synapomorphies were identified for this clade. The trait inference analysis did not support the grouping of these species under a single genus. Instead, splitting the clade into three genera would appear a better option (see Fig. S5). We discuss the resulting genus hypotheses below:

Genus hypothesis 1) This subclade is fully supported (bs: 100; PP: 1) and includes taxa morphologically assigned to $P$. capitatus (type species of the genus Penicillus), Udotea cyathiformis, $U$. conglutinata, $U$. sp9 and the two species of Rhipocephalus (R. phoenix and R. oblongus). It is interesting to note that Rhipocephalus species used to belong to Penicillus until Kützing (1843a and b) described the former. Various authors also highlighted the soft morphological boundaries between the genera Penicillus, Rhipocephalus and Udotea (Farghaly, 1980; Kooistra, 2002). Morphologically, species in this subclade are relatively coherent and differ only by the type of siphons' arrangement (forming a coherent blade or free) and the organization 
of the frond (unique or composed). In light of this information, we believe that the most likely genus hypothesis for this clade is Penicillus.

Genus hypothesis 2) The second highly supported subclade (bs: 100; PP:1, Fig. S5) of the "PRRU complex" includes species assigned to Penicillus dumetosus, $P$. pyriformis and $P$. lamourouxii (the latter was not included in the multilocus analysis since only one $r b c L$ sequence was available, but see Figure S2). All species in this subclade are morphologically similar with a capitate (brush-shaped) frond, large siphon diameters, wide and prominent stipe appendages, with pointed ( $P$. dumetosus, $P$. pyriformis) or finger like (P. lamourouxii) apices. Interestingly, Kützing (1849) already had proposed to consider these species, among others, as part of a distinct genus, Corallocephalus, but this latter was considered as a synonym of Penicillus.

Genus hypothesis 3) The third subclade is represented by the species Rhipidosiphon floridensis only (Fig. S5 SI). However, based on the results of Lagourgue et al. (2018) and Figures S1 \& S2, it is possible that Udotea spinulosa and U. looensis belong to same subclade. The situation would be similar for other Udotea species such as $U$. luna or $U$. verticillosa, which have never been sequenced but are morphologically close to Udotea spinulosa and $U$. looensis. All these species have a flabellate frond (mono or pluristromatic) composed of naked siphons or with protuberances (only on the outer face of the external siphons or at the base of the frond) and of large diameter $(\approx 50-100 \mu \mathrm{m})$. Additional work, particularly sequencing, is needed to confirm this clade as a genus and the species that should be included in it.

Finally, the "PRRU complex" shows strong morphological discontinuities in this study, and more data are needed (specimens per species, genetic data; some species 
are still not genetically represented) in order to better identify the species diversity, as well as the number, composition, and phylogenetic position of the different genera included in this complex. Therefore, we choose to postpone any taxonomic decisions about the "PRRU complex" until more data is available.

\subsubsection{The “Poropsis Penicillus Rhipidodesmis complex” (PPR complex- Clade I)}

This clade includes three taxa: an unknown Poropsis sp., Penicillus nodulosus and Chlorodesmis caespitosa (Figure S6).

Poropsis sp. - Our results point out to several entities from various localities (Hawai' $\mathrm{i}$, Israel, Mexico; see Figures S1 \& S2), which could be considered under the name Poropsis, a genus previously thought to be monospecific. However, because of missing data, only one taxon was included in the multilocus analyses and is represented in Figure S6 as Poropsis sp. Our trait inference analysis highlighted numerous symplesiomorphies and synapomorphies, which could be useful for describing the genus. The symplesiomorphic characters include calcification, an unique tufted frond, a creeping and upright axis, a non-ramified and multisiphonous stipe, continuous stipe-frond junction, dichotomous siphon ramifications, primary siphons arranged in one plane, isomorphic dichotomies and supra-dichotomial constrictions. Synapomorphies include a reduced rhizoidal system, absence of secondary structures in frond and stipe siphons, aligned dichotomies, symmetrical constrictions and absence of frond and stipe cortication.

Penicillus nodulosus - Following our proposed revision of the genus Penicillus above, P. nodulosus needs to be reassigned to a different genus. However, at this stage, we are missing sufficient data to make this taxonomic revision. We need genetic 
information about other presumed Indo-Pacific Penicillus species and their phylogenetic relationships among the Udoteaceae, particularly, their position within or outside this complex. Additional data is needed about the complex itself as well as the closely related species, to assess whether this species should be transferred to a particular genus or whether it should be grouped together with the other two in a same genus.

Chlorodesmis caespitosa - Our redefinition of the genus Chlorodesmis s.s. above, led us to reconsider the species Chlorodesmis caespitosa. Interestingly, Gepp \& Gepp (1911) proposed the genus Rhipidodesmis to accommodate the species, because it differs from other Chlorodesmis species by their apical branching, thicker upper filaments and the absence of moniliform and radicelliferous basal filaments. However, this was never validated taxonomically. We propose to validate the combination proposed by Gepp \& Gepp (1911), including their original diagnosis, and to rename Chlorodesmis caespitosa (J. Agardh) as Rhipidodesmis caespitosa (J. Agardh) A. Gepp \& E.S. Gepp. Also, our ancestral reconstructions of character states identified several symplesiomorphies and synapomorphies supporting and documenting the description of the genus Rhipidodesmis: the genus has a unique tufted frond, with dichotomous siphon ramifications and constrictions above the dichotomies. These three character states are symplesiomorphic. Also, the genus has several synapomorphic character states: it is not calcified, has a discoid holdfast and an upright axis but no stipe; The primary siphons are arranged in one plane, interwoven, with anisomorphic and aligned dichotomies, above which the constrictions are symmetric, but do not have secondary structures, and the frond is uncorticated.

This article is protected by copyright. All rights reserved. 
Rhipidodesmis A. Gepp \& E.S. Gepp

Diagnosis: Gepp A, Gepp ES. 1911. The codiaceae of the Siboga Expedition, including a monograph of Flabellarieae and Udoteaceae. Siboga-Expeditie 62: 1-150.

Type species: Rhipidodesmis caespitosa (J. Agardh) Gepp \& Gepp comb. nov.

\section{Morphological description emended from Gepp \& Gepp (1911): Plant}

filamentous, gregarious, laxly caespitose, uncalcified, composed of a discoid holdfast, and an upright axis consisting of an unique uncorticated tufted frond but no stipe; Base decubent, colourless and irregularly ramified, very laxly entangled (never densely felted so as to form a spurious stipes); Ascending above, viridescent, fastigiately or flabellately ramified towards the apex; Siphons with dichotomous ramifications (anisomorphic) and evenly (symmetrically) constricted above the dichotomies; Upper dichotomies approximated. Siphons lacking secondary structures.

Geographical distribution (confirmed using DNA sequencing): Pacific Ocean: New Caledonia (Grande Terre, Surprises Is.) (This study), Papua New Guinea (This study), Hawai‘i (Wade \& Sherwood, 2017), Clipperton (This study). See Guiry \& Guiry (2020) for a more detailed distribution in the Indo-Pacific.

Rhipidodesmis caespitosa (J. Agardh) Gepp \& Gepp

Type: Ferguson, $\mathrm{n}^{\circ} 110$

Type locality: Ceylon, Colombo, Sri Lanka

Etymology: Latin adjective for growing in patches or tufts, caespitose (Stearn 1973) 
Basionym: Chlorodesmis caespitosa J.Agardh (Agardh JG. 1887. Till Algernes Systematik.Nya bidrag. Acta Universitatis Lundensis 23: 1-174, 5 plates)

Synonymes: Avrainvillea caespitosa (J.Agardh) G.Murray \& Boodle; Chlorodesmis formosana Yamada

Description: see Gepp \& Gepp (1911).

Geographical distribution (confirmed using DNA sequencing): Pacific Ocean (confirmed with DNA sequencing): New Caledonia (Grande Terre, Surprises Is.) (This study), Papua New Guinea (This study), Hawai‘i (Wade \& Sherwood, 2017), Clipperton (This study). See Guiry \& Guiry (2020) for a more detailed distribution in the Indo-Pacific.

List of vouchers from this study (limited to 2 per locality): New Caledonia, Grande Terre, 2017: NOU203812; New Caledonia, Surprises Is., 2017: NOU203898; Papua New Guinea, Kavieng, 2014: NOU203345; Hawai‘i, O‘ahu, 2013:HADL01229; Clipperton, 2010: NOU203464, NOU203470.

The phylogenetic relationships between the three taxa in this clade are strongly supported (bs: 100; PP: 1), and it would also be acceptable to group them under the same genus (Figure S6). The three taxa share several morphological characters including the shape of their monoliform siphons, with deep constrictions at the dichotomies or between them. Within this clade, $P$. nodulosus has a brush-like gross morphology, and differs from the two other taxa which are delicate and filamentous. However, $P$. nodulosus also has a filamentous form in its life cycle, as described by Harvey (1858) - monoliformous and ramified filaments arising directly from the matted-root fibres (i.e., lack of stipe) -, such as the form P. capitatus f. mediterraneus 
(Decaisne) Huve \& Huve (i.e., “ex-Espera”). This filamentous form was found in our specimens of $P$. nodulosus, was confirmed genetically as belonging to the species, and could correspond to that observed by Harvey (1858). Therefore, we could hypothesize that the filamentous forms of Poropsis sp. and Rhipidodesmis caespitosa are lifestages of a more complex morphological species and considering these three taxa as part of the same genus could make sense. Conversely, numerous species hypotheses were identified in the species delimitation analyses (Fig S1 \& S2) but could not be included in our multilocus phylogeny due to missing genetic data. Thus, it is likely that clade I is more diverse than currently observed in our analyses, and could be composed of several genera. Larger sampling is therefore essential to correctly delineate the species and their geographical distributions before taxonomic decisions are made for the "PPR complex"..

\section{CONCLUSION}

Based on a total of 43 delimited species, our multilocus phylogeny revealed the monophyly of the family Udoteaceae, whereas most of its genera were polyphyletic. We propose to 1) revise the genera Udotea s.s., Rhipidosiphon s.s. and Chlorodesmis s.s.; 2) describe three new genera: Glaukea gen. nov., Ventalia gen. nov., and Udoteopsis gen. nov.; and 3) validate Gepp \& Gepp’s genus Rhipidodesmis. None of these delimited genera or their species appeared pantropical. For the first time, we produced a time-calibrated phylogeny of the family Udoteaceae. We inferred the evolution of its morpho-anatomical trait, and the taxonomic relevance of each morpho-anatomical character, for the diagnosis of the revised genera was reassessed. Numerous homoplasies were identified that remain useful for delimitating the different genera if combined with other characters. They also represent evidence of 
particular patterns of evolution during the diversification of Udoteaceae, such as parallel or convergent morphological evolutions or adaptations. Additionally, numerous symplesiomorphies and synapomorphies were identified and their relevance for genus-level identification was confirmed. Further study focusing on Core Halimedineae or Bryopsidales would provide information about the evolutionary patterns and taxonomic relevance of the various character states at a wider scale. Finally, considering the Udoteaceae species and genus richness, as well as their molecular and morphological diversity highlighted in this study, we believe that the taxonomic changes proposed by Cremen et al. (2019), particularly the proposal of downgrading family Udoteaceae to tribe is not justified.

\section{Acknowledgments}

This work was supported by the DUNE Labex-CORAIL project and ENTROPIE funds. The authors are thankful the Murray foundation and EUROMARINE for the grants that made this work possible. The authors are also grateful to Florence Rousseau, Line Le Gall, Elvan Ampou, Heroen Verbruggen and Chiela Cremen for providing additional samples or sequences. Thanks to Lydiane Mattio for proofreading the manuscript and her valuable advice. Samples were collected during several campaigns and by various collectors who we would like to acknowledge here: Bunaken, 2014: Sample collection and DNA analyses were made possible thanks to the INDESO project, under the research permit 133/SIP/FRP/SM/V/2015 and 918/BLITBANKKP/II/2016 issued by the Indonesian government and under a material transfer agreement between BALITBANG KP (now BRSDM KP, Ministry of Maritime Affairs and Fisheries) and the IRD; Clipperton, 2010: "Passion 2015" project financed by the «Agence française de Développement » and the Pacific Fund; 
Fiji, 2007: R/V Alis, BSM-Fidji, http://dx.doi.org/10.17600/7100030; French Polynesia, 2013: LOF; Kavieng, 2014: http://dx.doi.org/10.17600/14004400; Madagascar, 2010: Atimo Vatae, http://dx.doi.org/10.17600/10110040; 2016: R/V Antea, MAD http://dx.doi.org/10.17600/16004700; Madang, 2012: R/V Alis, NUIGUINI campaign http://dx.doi.org/10.17600/12100070; Maldive Is., 2009: Sampling was performed with the Marine Research Center of Maldives during the 2009 Baa Atoll expedition, which did not require collection permits; Mayotte, 2010: TARA; 2016: SIREME; New Caledonia, 2005: R/V Alis, BSM-LOYAUTE: http://dx.doi.org/10.17600/5100030; 2008: CORALCAL2 http://dx.doi.org/10.17600/8100050; 2012: CORALCAL4 http://dx.doi.org/10.17600/12100060; 2013: LOF; 2015: R/V Alis, CHEST http://dx.doi.org/10.17600/15004500; 2017: R/V Alis PostBlanco1 \& TARA-NC; Scattered Islands, Glorioso Is. (2012) \& Juan de Nova Is. (2013): BIORECIE; Solomon Islands, 2004: R/V Alis, BSM-Salomon; Tonga, 2013: PRISTINE; Vanuatu, 2006: SANTO, http://dx.doi.org/10.17600/6100100.

\section{References}

Adamowicz SJ, Purvis A, Wills MA. 2008. Increasing morphological complexity in multiple parallel lineages of the Crustacea. Proceedings of the National Academy of Sciences 105: 4786-4791.

Agardh JG. 1887. Till Algernes Systematik.Nya bidrag. Acta Universitatis Lundensis 23: 1-174, 5 plates.

Blomberg SP, Garland T, Ives AR. 2003. Testing for phylogenetic signal in comparative data: Behavorial traits are more labile. Evolution 57: 717-745.

This article is protected by copyright. All rights reserved. 
Bouckaert R, Heled J, Kühnert D, Vaughan T, Wu CH, Xie D, Suchard MA, Rambaut A, Drummond AJ. 2014. BEAST 2: A Software Platform for Bayesian Evolutionary Analysis (A Prlic, Ed.). PLoS Computational Biology 10: e1003537.

Carstens BC, Knowles LL. 2007. Estimating Species Phylogeny from Gene-Tree Probabilities Despite Incomplete Lineage Sorting: An Example from Melanoplus Grasshoppers. Syst. Biol 56: 400-411.

Carstens BC, Pelletier TA, Reid NM, Satler JD. 2013. How to fail at species delimitation. Molecular Ecology 22: 4369-4383.

Chesters D. 2013. Collapsetypes.pl. Available at: < https://sourceforge.net/projects/

collapsetypes >

Collado-Vides L, Suárez A, Cabrera R. 2009. Una revisión taxonómica del género Udotea en el Caribe mexicano y cubano. Rev. Invest. Mar 30: 145-161.

Coppejans E, Leliaert F, Dargent O, De Clerck O. 2001. Marine green algae (Chlorophyta) from the north coast of Papua New Guinea. Cryptogamie, Algol., 22: 375-443.

Coppejans E, Leliaert F, Verbruggen H, Prathep A, De Clerck O. 2011. Rhipidosiphon lewmanomontiae sp. nov. (Bryopsidales, Chlorophyta), a calcified udoteacean alga from the central Indo-Pacific based on morphological and molecular investigations. Phycologia 50: 403-412.

This article is protected by copyright. All rights reserved. 
Cremen MCM, Leliaert F, West J, Lam DW, Shimada S, Lopez-Bautista JM, Verbruggen H. 2019. Reassessment of the classification of Bryopsidales (Chlorophyta) based on chloroplast phylogenomic analyses. Molecular Phylogenetics and Evolution 130: 397-405.

Curtis NE, Dawes CJ, Pierce SK. 2008. Phylogenetic analysis of the large subunit rubisco gene supports the exclusion of Avrainvillea and Cladocephalus from the Udoteaceae (Bryopsidales, Chlorophyta). Journal of Phycology 44: 761767.

Dayrat B. 2005. Towards integrative taxonomy. Biol. J. Linn. Soc. Lond. 85: 407415.

Decaisne J. 1842. Mémoire sur les corallines ou polypiers calcifères. Annales des Sciences Naturelles, Botanique, Seconde Série 18: 96-128.

Dragastan O, Richter DK, Kube B, Popa M, Sarbu A, Ciugulea I. 1997. A new family of paleo-mesozoic calcareous green siphons-algae (Order Bryopsidales, Class Bryosidophyceae, Phylum Siphonophyta). Rev. Espanola de Micropaleontologia 29: 69-135.

Drummond AJ, Ho SYW, Phillips MJ, Rambaut A. 2006. Relaxed Phylogenetics and Dating with Confidence (D Penny, Ed.). PLoS Biology 4: 699-710.

Drummond AJ, Xie W, Heled J. 2012. Bayesian Inference of Species Trees from Multilocus Data using * BEAST.: 1-18.

Dubois A. 2007. Naming taxa from cladograms: A cautionary tale. Molecular Phylogenetics and Evolution 42: 317-330.

This article is protected by copyright. All rights reserved. 
Ducker SC. 1965. The Structure and Reproduction of the Green Alga Chlorodesmis bulbosa. Phycologia 4: 149-162.

Ducker S. 1967. The genus Chlorodesmis (Chlorophyta) in the Indo-Pacific region. Nova Hedwigia 13: 145-182.

Dupuis JuR, Roe AD, Sperling FAH. 2012. Multi-locus species delimitation in closely related animals and fungi: one marker is not enough. Molecular Ecology 21: 4422-4436.

Egerod LE. 1952. An analysis of the siphonous Chlorophycophyta with special reference to the Siphonocladales, Siphonales, and Dasycladales of Hawaii. Univ. Calif. Publ. Bot 25: 327-367.

Farghaly M. 1980. Algues Benthiques de la Mer Rouge et du bassin occidental de l’océan Indien. Unpublished thesis, Université des sciences et techniques du Languedoc.

Fiore M. 1936. Di un’alga fossile nuova per la “Pesciara” di Bolca, Nota.

Friedmann EI, Roth WC. 1977. Development of the siphonous green alga Penicillus and the Espera state. Botanical Journal of the Linnean Society 74: 189-214.

Fritz SA, Purvis A. 2010. Selectivity in mammalian extinction risk and threat types: A new measure of phylogenetic signal strength in binary traits. Conservation Biology 24: 1042-1051.

Fujita MK, Leache AD, Burbrink FT, Mcguire JA, Moritz C. 2012. Coalescent- 
based species delimitation in an integrative taxonomy. Trends Ecol. Evol.. 27: 480-488.

Garbino GST, Martins-Junior AMG. 2018. Phenotypic evolution in marmoset and tamarin monkeys (Cebidae, Callitrichinae) and a revised genus-level classification. Molecular Phylogenetics and Evolution 118: 156-171.

Gepp A, Gepp ES. 1911. The codiaceae of the Siboga Expedition, including a monograph of Flabellarieae and Udoteaceae. Siboga-Expeditie 62: 1-150.

Goreau TF. 1963. Calcium carbonate deposition by coralline algae and corals in relation to their roles as reef-builders. Annals of the New York Academy of Sciences 109:127-67.

Granier B. 2012. The contribution of calcareous green algae to the production of limestones: a review. Geodiversitas 34, 35-60. doi:10.5252/g2012n1a3

Guiry MD, Guiry GM. 2020. AlgaeBase. World-wide electronic publication, National University of Ireland, Galway. http://www.algaebase.org; searched on 13 January 2020

Gustavson TC, Delevoryas T. 1992. Caulerpa-like marine alga from Permian strata, Palo Duro Basin, West Texas. Journal of Paleontology 66: 160-161.

Händeler K, Wägele H, Wahrmund U, Rüdinger M, Knoop V. 2010. Slugs’ last meals: molecular identification of sequestered chloroplasts from different algal origins in Sacoglossa (Opisthobranchia, Gastropoda). Molecular Ecology Resources 10: 968-978.

This article is protected by copyright. All rights reserved. 
Harmon LJ, Weir JT, Brock CD, Glor RE, Challenger W. 2008. GEIGER: Investigating evolutionary radiations. Bioinformatics 24: 129-131.

Harvey WH, Bailey JW. 1851. Description of seventeen new species of algae, collected by the United States Exploring Expedition. Proc. Boston Soc. Nat. Sci. 3: 370-373.

Hay ME, Kappel QE, Fenical W. 1994. Synergisms in Plant Defenses against Herbivores: Interactions of Chemistry, Calcification, and Plant Quality. Ecology 75: 1714-1726.

Heled J, Drummond AJ. 2012. Calibrated Tree Priors for Relaxed Phylogenetics and Divergence Time Estimation. Systematic Biology 61: 138-149.

Hillis-Colinvaux L. 1984. Systematics of the Siphonales. Irvine, D. E. G. \& John, D. M. [Eds.] Systematics of the Green Algae. London and Orlando, Florida, 271-296.

Itono I. 1973. Notes on Marine Algae from Hateruma Island, Ryukyu. Botanical Magazine, Tokyo 86: 155-168.

Kapli P, Lutteropp S, Zhang J, Kobert K, Pavlidis P, Stamatakis A, Flouri T. 2017. Multi-rate Poisson Tree Processes for single-locus species delimitation under Maximum Likelihood and Markov Chain Monte Carlo. Bioinformatics 29: btx025.

Kearse M, Moir R, Wilson A, Stones-Havas S, Cheung M, Sturrock S, Buxton S, Cooper A, Markowitz S, Duran C, Thierer T, Ashton B, Meintjes P, Drummond A. 2012. Geneious Basic: An integrated and extendable desktop 
software platform for the organization and analysis of sequence data. Bioinformatics 28: 1647-1649.

Kooistra WHCF. 2002. Molecular phylogenies of Udoteaceae (Bryopsidales, Chlorophyta) reveal nonmonophyly for Udotea, Penicillus and Chlorodesmis. Phycologia 41: 453-462.

Kooistra WCF, Coppejans EGG, Payri C. 2002. Molecular systematics, historical ecology, and phylogeography of Halimeda (Bryopsidales). Molecular Phylogenetics and Evolution 24: 121-138.

Kützing FT. 1843a. Phycologia generalis oder Anatomie, Physiologie und Systemkunde der Tange (F. A. Brockhaus, Ed.). Leipzig: Brockhaus, F. A.

Kützing FT. 1843b. Ueber die Systematische Eintheilung der Algen. Linnaea 17: 75-107.

Kützing FT. 1849. Species Algarum (FA Brockhaus, Ed.). Lipsiae [Leipzig]: Brockhaus, F. A.

Lagourgue L, Puillandre N, Payri CE. 2018. Exploring the Udoteaceae diversity (Bryopsidales, Chlorophyta) in the Caribbean region based on molecular and morphological data. Molecular Phylogenetics and Evolution 127: 758-769.

Lam DW, Zechman FW. 2006. Phylogenetic analyses of the Bryopsidales (Ulvophyceae, Chlorophyta) based on Rubisco large subunit gene sequences. Journal of Phycology 42: 669-678.

Lamouroux JVF. 1812. Sur la classification des polypiers coralligènes non 
entièrement pierreux. Nouveaux Bulletin des Sciences, Societé philomatiques de Paris 3: 181-188.

Lanfear R, Calcott B, Ho SYW, Guindon S. 2012. PartitionFinder: Combined Selection of Partitioning Schemes and Substitution Models for Phylogenetic Analyses. Molecular Biology and Evolution 29: 1695-1701.

Leliaert F, Verbruggen H, Vanormelingen P, Steen F, López-Bautista JM, Zuccarello GC, De Clerck O. 2014. DNA-based species delimitation in algae. European Journal of Phycology.

Littler DS, Littler MM. 1990a. Systematics of Udotea species (Bryopsidales, Chlorophyta) in the tropical western Atlantic. Phycologia 29: 206-252.

Littler DS, Littler MM. 1990b. Reestablishment of the green algal genus Rhipidosiphon Montagne (Udoteaceae, Bryopsidales) with a description of Rhipidosiphon floridensis sp. nov. British Phycological Journal 25: 33-38.

Littler MM, Littler DS. 1999. Blade abandonment/proliferation: A novel mechanism for rapid epiphyte control in marine macrophytes. Ecology 80: 1736-1746.

Littler DS, Littler MM. 2000. Caribbean Reef Plants: An Identification Guide to the Reef Plants of the Caribbean, Bahamas, Florida and Gulf of Mexico (I Offshore Graphics, Ed.). Washington, D.C.

Meinesz A. 1972. Sur la croissance et le développement du Penicillus capitatus Lamarck forma mediterranea (Decaisne) P. et H. Huv, (Caulerpale, Udot,ac,e). Comptes Rendus de l'Acad,mie des Sciences Paris 275: 667-669. 
Meinesz A. 1975. Premières observations sur la reproduction du Penicillus capitatus Lamarck forma mediterranea (Decaisne) P. et H. Huve (Caulerpale, Udoteacee). Annales du Museum d'Histoire Naturelle de Nice 3: 19-20.

Meinesz A. 1980. Connaissances actuelles et contribution à l'étude de la reproduction et du cycle des Udotéacées (Caulerpales, Chlorophytes). Phycologia 19: 110-138.

Miller MA, Pfeiffer W, Schwartz T. 2010. Creating the CIPRES Science Gateway for inference of large phylogenetic trees. 2010 Gateway Computing Environments Workshop (GCE). IEEE, 1-8.

Monaghan MT, Wild R, Elliot M, Fujisawa T, Balke M, Inward DJG, Lees DC, Ranaivosolo R, Eggleton P, Barraclough TG, Vogler AP. 2009. Accelerated species Inventory on Madagascar using coalescent-based models of species Delineation. Systematic Biology 58: 298-311.

Montagne JFC. 1842. Prodromus generum specierumque phycearum novarum, in itinere adpolum antarcticum...collectarum. Paris. 16 pp.

Nizamuddin M. 1963. Studies on the Green Alga, Udotea indica A. \&amp; E. S. Gepp, 1911. Pacific Science 17: 243-245.

Orme D. 2013. The caper package: comparative analysis of phylogenetics and evolution in R.

Pagel M. 1999. Inferring the historical patterns of biological evolution. Nature 401: 877-884.

This article is protected by copyright. All rights reserved. 
Payri CE. 2000. Production primaire et calcification des algues benthiques en milieu corallien. Océanis 26, 427-463

Payri CE, Verbruggen H. 2009. Pseudocodium mucronatum, a new species from new caledonia, and an analysis of the evolution of climatic preferences in the genus (Bryopsidales, Chlorophyta). Journal of Phycology 45: 953-961.

Pigliucci M. 2008. Is evolvability evolvable? Nature Reviews Genetics 9: 75-82.

Poncet J. 1989. Presence du genre Halimeda Lamouroux, 1812 (algue verte calcaire) dans le Permien Supérieur du Sud Tunisien. Revue Micropaleontologie 32: 40-44.

Pons J, Barraclough TG, Gomez-zurita J, Cardoso A, Duran DP, Hazell S, Kamoun S, Sumlin WD, Vogler AP. 2006. Sequence-Based Species Delimitation for the DNA Taxonomy of Undescribed Insects. Syst. Biol 55: 595-609.

Puillandre N, Lambert A, Brouillet S, Achaz G. 2012a. ABGD, Automatic Barcode Gap Discovery for primary species delimitation. Molecular Biology and Evolution: 1864-1877.

Puillandre N, Modica MV, Gustave O, Place LL, West CP. 2012b. Large-scale species delimitation method for hyperdiverse groups. Molecular Ecology: 121.

R Development Core Team. 2019. R: A language and Environment for Statistical Computing. 
Rabosky DL, Santini F, Eastman J, Smith SA, Sidlauskas B, Chang J, Alfaro ME. 2013. Rates of speciation and morphological evolution are correlated across the largest vertebrate radiation. Nature Communications 4: 1-8.

Rambaut A, Drummond A. 2007. Tracer version 1.5.

Rannala B. 2015. The art and science of species delimitation. Current Zoology.

Reid NM, Carstens BC. 2012. Phylogenetic estimation error can decrease the accuracy of species delimitation: a Bayesian implementation of the general mixed Yule-coalescent model. BMC Evolutionnary Biology: 1-11.

Revell LJ. 2012. phytools: an R package for phylogenetic comparative biology (and other things). Methods in Ecology and Evolution 3: 217-223.

Ries J.B. 2006. Aragonitic algae in calcite seas: effect of seawater mg/ca ratio on algal sediment production. Journal of Sedimentary Research. 76, 515-523. doi:10.2110/jsr.2006.051

Ronquist F, Huelsenbeck JP. 2003. MrBayes 3: Bayesian phylogenetic inference under mixed models. Bioinformatics (Oxford, England) 19: 1572-4.

Saunders GW, Kucera H. 2010. An evaluation of rbcL, tufA, UPA, LSU and ITS as DNA barcode markers for the marine green macroalgae. Cryptogamie Algologie: 487-528.

Sauvage T, Ballantine DL, Peyton KA, Wade RM, Sherwood AR, Keeley S, Smith C. 2019. Molecular confirmation and morphological reassessment of Udotea geppiorum (Bryopsidales, Chlorophyta) with ecological observations 
of mesophotic meadows in the Main Hawaiian Islands. European Journal of Phycology 00: 1-11.

Sauvage T, Payri CE, Draisma SG, Prud WF, Van Reine H, Verbruggen H, Belton GS, Frederico Gurgel CD, Gabriel D, Sherwood AR, Fredericq S, Sga D, Van Reine HW, Cfd G. 2013. Molecular diversity of the Caulerpa racemosaCaulerpa peltata complex (Caulerpaceae, Bryopsidales) in New Caledonia, with new Australasian records for C. racemosa var. cylindracea. Phycologia 52: 6-13.

Sauvage T, Schmidt WE, Suda S, Fredericq S. 2016. A metabarcoding framework for facilitated survey of endolithic phototrophs with tufA. BMC Ecology 16: 121.

Schlick-Steiner BC, Steiner FM, Seifert B, Stauffer C, Christian E, Crozier RH. 2010. Integrative Taxonomy: A Multisource Approach to Exploring Biodiversity. Annual Review of Entomology 55: 421-438.

Stamatakis A. 2014. RAxML version 8: a tool for phylogenetic analysis and postanalysis of large phylogenies. Bioinformatics 30: 1312-1313.

Stamatakis A, Hoover P, Rougemont J, Renner S. 2008. A Rapid Bootstrap Algorithm for the RAxML Web Servers. Systematic Biology 57: 758-771.

Talavera G, Dinc V, Vila R. 2013. Factors affecting species delimitations with the GMYC model: insights from a butterfly survey. 1101-1110.

Tamura K, Stecher G, Peterson D, Filipski A, Kumar S. 2013. MEGA6: Molecular Evolutionary Genetics Analysis version 6.0. Molecular biology and evolution 
30: 2725-9.

Taylor WR. 1945. Pacific marine algae of the Allan Hancock Expedition to the Galapagos Islands. Allan Hancock Pacific Expeditions 12: 1-518.

Thiers B. 2018. Index Herbariorum: A Global Directory of Public Herbaria and Associated Staff. New York Botanical Garden’s Virtual Herbarium.

Trono GC. 1971. Some new species of marine benthic algae from the Caroline Islands, western-central Pacific. Micronesica 7: 45-77.

Tseng CK, Dong ML. 1975. Some new species of Udotea from the Xisha Islands, Guangdong Province, China. Studia Marina Sinica 10: 1-19, pls I, II.

Tseng CK, Dong ML. 1978. Studies on some marine green algae from the Xisha Islands, Guangdong Province, China. I. Studia Marina Sinica 12: 41-50.

Verbruggen H, Ashworth M, LoDuca ST, Vlaeminck C, Cocquyt E, Sauvage T, Zechman FW, Littler DS, Littler MM, Leliaert F, De Clerck O. 2009b. A multi-locus time-calibrated phylogeny of the siphonous green algae. Molecular Phylogenetics and Evolution 50: 642-653.

Verbruggen H, De Clerck O, Cocquyt E, Kooistra WHCF, Coppejans E. 2005a. Morphmetric taxonomy of siphonous green algae: a methodological study within the genus Halimeda (Bryopsidales). j.phycological 41: 126-139.

Verbruggen H, De Clerck O, Kooistra, Wiebe HCF, Coppejans E. 2005b. Molecular and morphometric data pinpoint species boundaries in Halimeda section Rhipsalis (Bryopsidales, Chlorophyta). j.phycological 41: 606-621. 
Verbruggen H, Leliaert F, Maggs CA, Shimada S, Schils T, Provan J, Booth D, Murphy S, De Clerck O, Littler DS, Littler MM, Coppejans E. 2007. Species boundaries and phylogenetic relationships within the green algal genus Codium (Bryopsidales) based on plastid DNA sequences. Molecular Phylogenetics and Evolution 44: 240-254.

Verbruggen H, Marcelino VR, Guiry MD, Cremen MCM, Jackson CJ. 2017. Phylogenetic position of the coral symbiont Ostreobium (Ulvophyceae) inferred from chloroplast genome data (L Graham, Ed.). Journal of Phycology 53: $790-803$.

Verbruggen H, Schils T. 2012. Rhipilia coppejansii, a new coral reef-associated species from Guam (Bryopsidales, Chlorophyta). Journal of Phycology 48: 1090-1098.

Verbruggen H, Tyberghein L, Pauly K, Vlaeminck C, Nieuwenhuyze K Van, Kooistra WHCF, Leliaert F, Clerck O De. 2009c. Macroecology meets macroevolution: evolutionary niche dynamics in the seaweed Halimeda. Global Ecology and Biogeography 18: 393-405.

Verbruggen H, Vlaeminck C, Sauvage T, Sherwood AR, Leliaert F, De Clerck O. 2009a. Phylogenetic analysis of pseudochlorodesmis strains reveals cryptic diversity above the family level in the siphonous green algae (bryopsidales, chlorophyta). Journal of Phycology 45: 726-731.

Vroom PS, Smith CM, Keeley SC. 1998. Cladistics of the Bryopsidales: A preliminary analysis. 360: 351-360.

This article is protected by copyright. All rights reserved. 
Wade RM, Sherwood AR. 2017. Molecular determination of kleptoplast origins from the sea slug Plakobranchus ocellatus (Sacoglossa, Gastropoda) reveals cryptic bryopsidalean (Chlorophyta) diversity in the Hawaiian Islands. Journal of Phycology 53: 467-475.

Wiens JJ. 2007. Species delimitation: new approaches for discovering diversity. Systematic biology 56: 875-878.

Wray, J. L. 1977. Calcareous Algae. Elsevier, Amsterdam, 185 pp

Zanardini G. 1858. Plantarum in mari Rubro hucusque collectarum enumerato (juvante A. Figari). Memoirie del Reale Istituto Veneto di Scienze, Lettere ed Arti 7: 209-309, pls III-XIV.

Zhang J, Kapli P, Pavlidis P, Stamatakis A. 2013. A general species delimitation method with applications to phylogenetic placements. Bioinformatics 29: 2869-2876.

This article is protected by copyright. All rights reserved. 
Table 1: Number of delimited PSHs, for each of the five methods applied to tufA and $r b c L$, including the number of singletons.

\begin{tabular}{|ccccccc|}
\hline Methods & & GMYC & bGMYC & hPTP & mPTP & ABGD \\
\hline $\begin{array}{c}\text { Number of } \\
\text { delimited PSHs } \\
\text { number of } \\
\text { singletons }\end{array}$ & tufA & $39 \mid 5$ & $43 \mid 8$ & $53 \mid 17$ & $50 \mid 14$ & $51 \mid 10$ \\
\cline { 2 - 7 } & rbcL & $49 \mid 13$ & $48 \mid 13$ & $56 \mid 27$ & $53 \mid 20$ & $55 \mid 17$ \\
\hline
\end{tabular}

Table 2: Main results of the trait evolution mapping for the discrete morphoanatomical characters having a phylogenetical signal and for which the ancestral state could be estimated for the Udoteaceae ancestor. Status of each character state (homoplasy, synapomophy or symplesiomorphy) is also reported.

\begin{tabular}{|c|c|c|}
\hline CHARACTERS & STATUS AND TAXONOMIC RELEVANCE & $\begin{array}{l}\text { STATE ESTIMATION FOR THE } \\
\text { UDOTEACEAE ANCESTOR }\end{array}$ \\
\hline Stipe (presence/absence) & $\begin{array}{l}\text { Presence: symplesiomorphy; Absence: } \\
\text { homoplasy/synapomorphy }\end{array}$ & Presence of stipe \\
\hline $\begin{array}{c}\text { Calcification } \\
\text { (presence/absence) }\end{array}$ & $\begin{array}{l}\text { Presence: symplesiomorphy; Absence: } \\
\text { homoplasy/synapomorphy }\end{array}$ & Calcified \\
\hline $\begin{array}{l}\text { Calcified siphons surface } \\
\text { porous or non-porous }\end{array}$ & Non-porous: symplesiomorphy; Porous: homoplasy & Non porous \\
\hline Stipe type & $\begin{array}{l}\text { Multisiphonous: symplesiomorphy; } \\
\text { Monosiphonous: homoplasy }\end{array}$ & Multisiphonous \\
\hline $\begin{array}{l}\text { Primary siphons } \\
\text { disposition }\end{array}$ & $\begin{array}{l}\text { On one plane: symplesiomorphy; On several planes: } \\
\text { homoplasy/synapomorphy }\end{array}$ & On one plane \\
\hline External habit (Growth) & $\begin{array}{l}\text { Creeping and upright axis: symplesiomorphy; Only } \\
\text { upright axis: synapomorphy }\end{array}$ & Creeping and upright \\
\hline Thallus cortication & $\begin{array}{l}\text { Total cortication: symplesiomorphy; Partial } \\
\text { cortication: homoplasy; } \\
\text { Absence of cortication: homoplasy/synapomorphy }\end{array}$ & Total cortication of the thallus \\
\hline
\end{tabular}

This article is protected by copyright. All rights reserved. 


\begin{tabular}{|c|c|c|}
\hline Frond shape & $\begin{array}{l}\text { Flabellate: symplesiomorphy; Capitate: homoplasy; } \\
\text { Caespitose: homoplasy/synapomorphy; } \\
\text { Axis with different structures: synapomorphy; } \\
\text { Cyathiform and filiform: autapomorphies }\end{array}$ & Flabellate \\
\hline Frond thickness & $\begin{array}{l}\text { Pluristromatic (or in tuft): symplesiomorphy; } \\
\text { Monostromatic: homoplasy/synapomorphy }\end{array}$ & Pluristromatic \\
\hline $\begin{array}{l}\text { Secondary structures on } \\
\text { the frond siphon }\end{array}$ & $\begin{array}{l}\text { Appendages: symplesiomorphy; Protuberances: } \\
\text { homoplasy; None: homoplasy/synapomorphy }\end{array}$ & Appendages \\
\hline Frond cortication & $\begin{array}{l}\text { Complete cortication: symplesiomorphy; } \\
\text { Incomplete cortication: homoplasy; } \\
\text { Absence of cortication: homoplasy/synapomorphy }\end{array}$ & Complete cortication of the frond \\
\hline Dichotomies alignment & $\begin{array}{l}\text { Not aligned: symplesiomorphy; Aligned: homoplasy; } \\
\text { Aligned only at the basis: homoplasy/synapomorphy }\end{array}$ & Not aligned \\
\hline Type of constrictions & $\begin{array}{l}\text { Asymmetrical: symplesiomorphy; Symmetrical: } \\
\text { homoplasy/synapomorphy }\end{array}$ & Asymmetrical \\
\hline $\begin{array}{l}\text { Secondary structures on } \\
\text { the stipe siphon }\end{array}$ & $\begin{array}{l}\text { Appendages: symplesiomorphy; Descending } \\
\text { laterals: homoplasy; } \\
\text { None: homoplasy/synapomorphy }\end{array}$ & Appendages \\
\hline Stipe cortication & $\begin{array}{l}\text { Complete cortication: symplesiomorphy; } \\
\text { Pseudocortex: homoplasy; } \\
\text { Absence of cortication: homoplasy/synapomorphy }\end{array}$ & Complete cortication of the stipe \\
\hline Stipe-frond junction & Continuous: symplesiomorphy; Sharp: homoplasy & Continuous \\
\hline
\end{tabular}

This article is protected by copyright. All rights reserved. 


\section{Figuress}

Figure 1. A, ML phylogeny produced using the multi-marker matrix (tufA, $r b c L$ and 18S rDNA) with bootstraps and posterior probabilities indicated at nodes (bs/PP). Species of the same genus as recognized by Guiry \& Guiry (2020, searched on January 2020) are indicated using the same color. (*) indicates type species. B, Condensed ML tree showing the nine clades (A-I) proposed for the taxonomic revision of Udoteaceae genera. Clades A, B, D and F represent current genera whose taxonomic boundaries are redefined in this study. Clades C, E, and G represent new genera, while the status of clades $\mathrm{H}$ and I remains unclear.

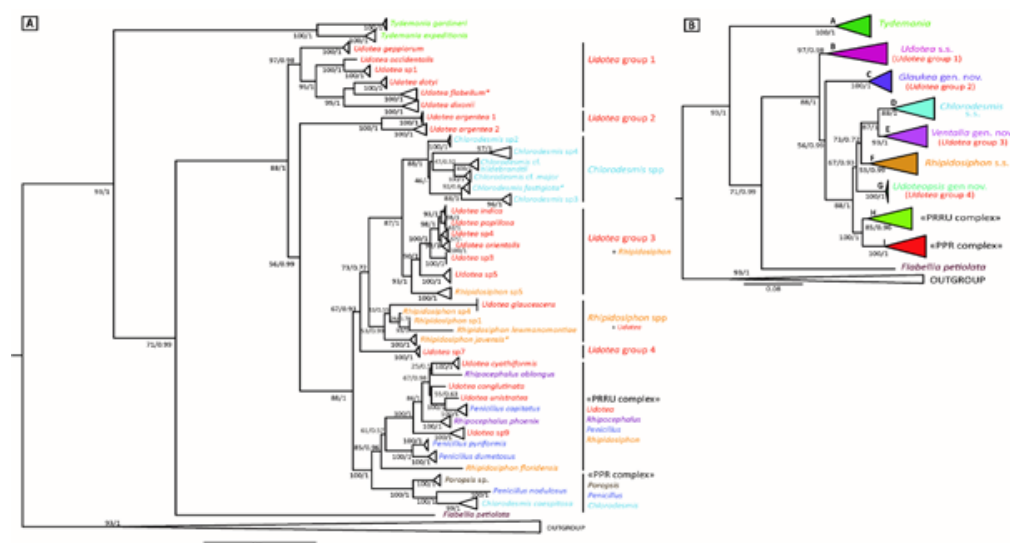

Figure 2. Time-calibrated phylogeny of the Udoteaceae from the BEAST analysis. Estimated divergence times are indicated at the nodes, and grey bars indicate the $95 \%$ HPD (highest probability densities). Black asterisks represent nodes supported for both the ML and Bayesian Inference methods ( $b s>85$; PP > 0.95), while grey asterisks represent nodes that are only supported in the BI analysis (PP > 0.95; bs < 85). Asterisks after taxon names indicate invalid genus or species requiring taxonomic revision.

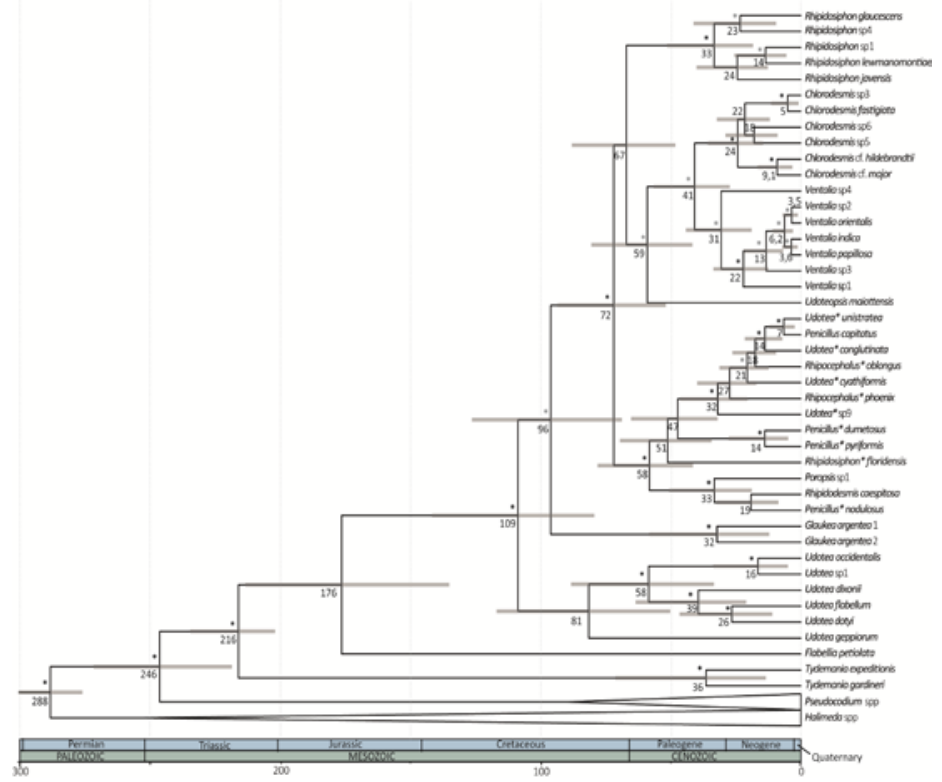

This article is protected by copyright. All rights reserved. 
Figure 3: Ancestral state reconstruction for A, Upright vegetative form; B, Thallus cortication; C, Presence or absence of calcification; and $\mathbf{D}$, Presence or absence of secondary structures on frond siphons. The analyses were carried out using MCCT resulting from the BEAST analysis and 1,000 iterations. Pie charts show the frequency of character states at each node.

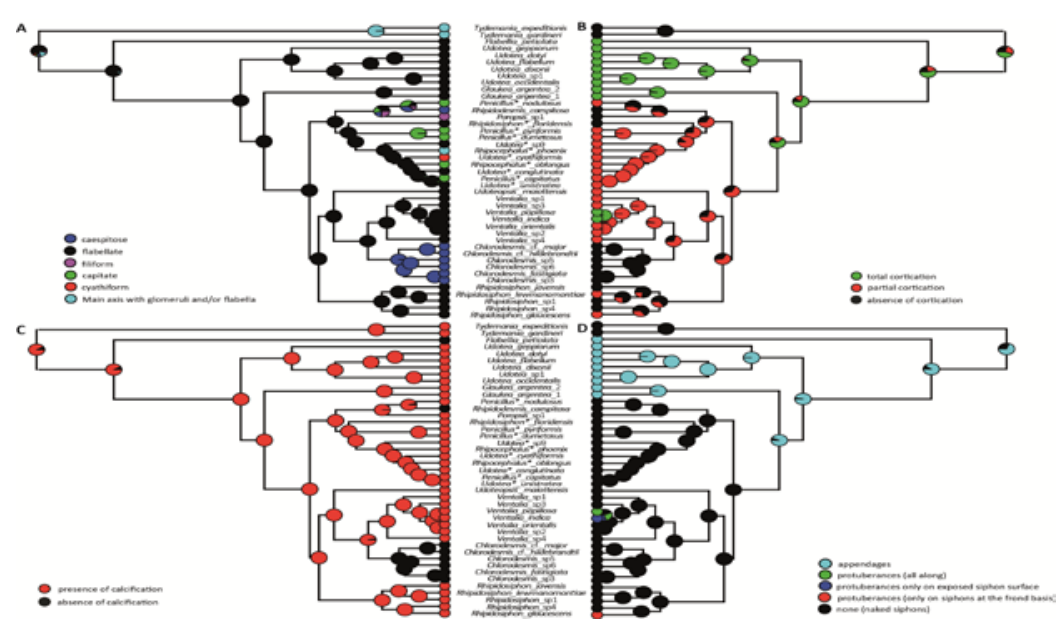

Figure 4. ML phylogeny of Udotea s.s. Bootstraps and Posterior probabilities (bs/PP) are indicated at nodes. Species hypotheses obtained using the five species delimitation methods on the two markers are shown on the right, along with allocated species names, illustrations and geographical distribution $(\mathrm{A}=U$. flabellum; $\mathrm{B}=U$. dotyi; $\mathrm{C}=\mathrm{U}$. dixonii; $\mathrm{D}=$ $\mathrm{U}$. occidentalis; $\mathrm{E}=\mathrm{U}$. geppiorum; $\mathrm{F}=U$. sp1). The genus symplesiomorphies and synapomorphies, which were identified by inferring morphological characters on the timecalibrated phylogeny, are shown on the left. Image rights: Payri, C.E.; Menou, J.L., Littler \& Littler $(2000 ; *)$.

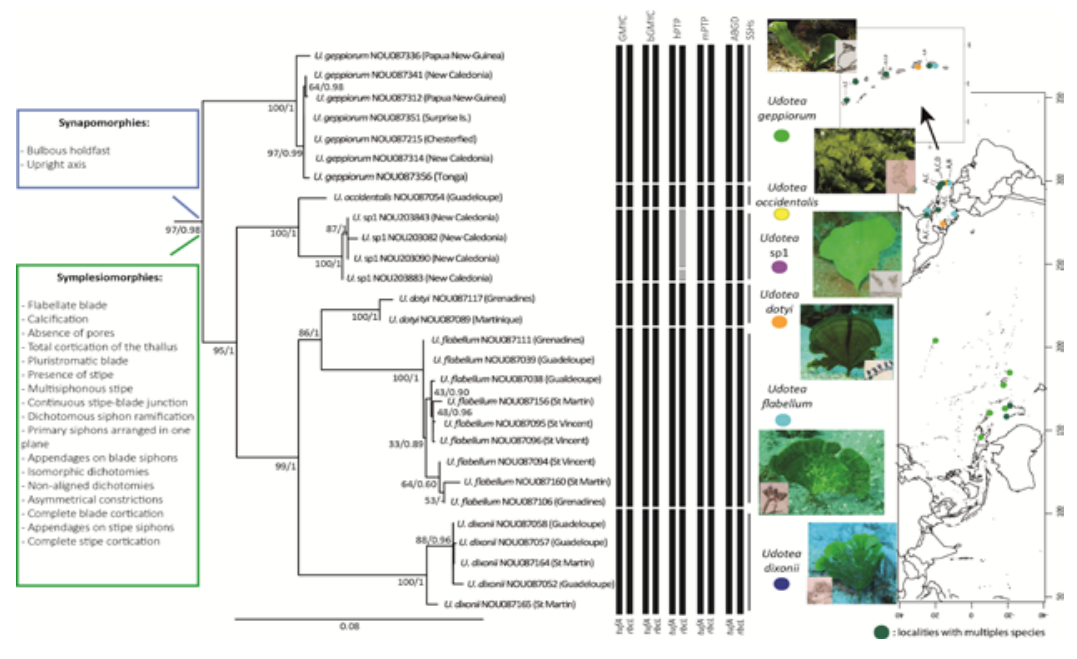

This article is protected by copyright. All rights reserved. 
Figure 5. Glaukea genus. A-D, Glaukea argentea 1 (NOU204097; NOU204098). A, Herbarium specimen. B, In situ specimen. C, Siphons with lobed appendages. D, Lobed appendages. E-H, G. argentea 2 (NOU203657, NOU203661). E, Herbarium specimen. F, In situ specimen. G, Siphons with lobed appendages. H, Lobed appendages; Scale bars: B= 4 cm; C= $80 \mu \mathrm{m} ; \mathrm{D}=57 \mu \mathrm{m} ; \mathrm{F}=2.3 \mathrm{~cm} ; \mathrm{G}=120 \mu \mathrm{m} ; \mathrm{H}=37.5 \mu \mathrm{m}$.

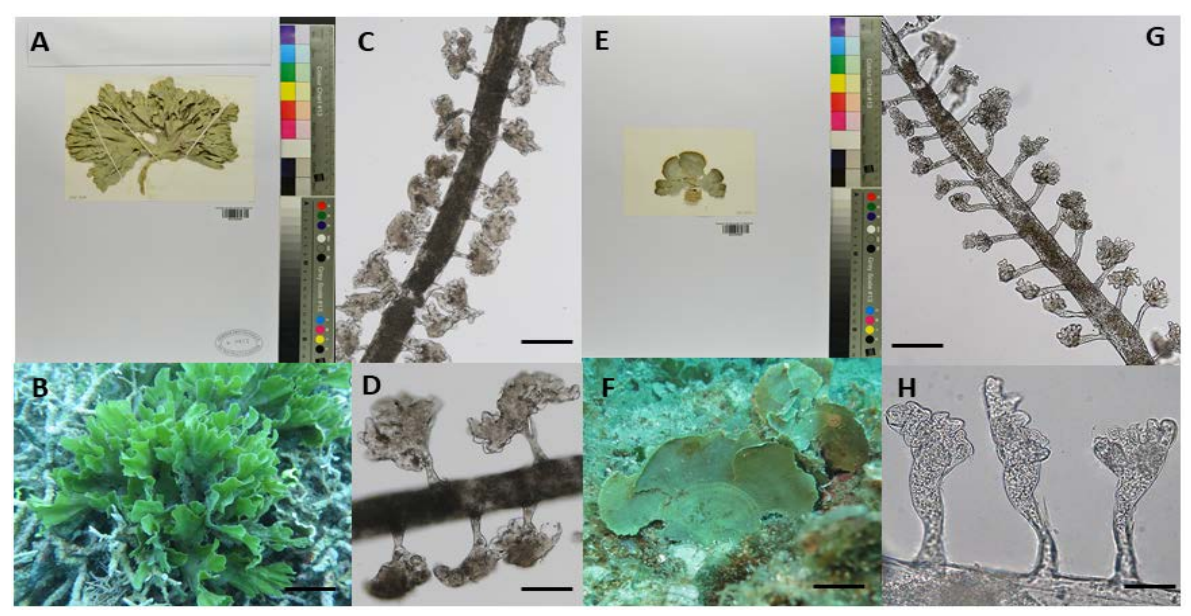

Figure 6. ML phylogeny of Chlorodesmis. Bootstraps and Posterior probabilities (bs/PP) are indicated at nodes. Species hypotheses obtained using the five species delimitation methods on the two markers are shown on the right, along with allocated species names, illustrations and geographical distribution $(\mathrm{B}=C$. $\mathrm{cf}$. hildebrandtii; $\mathrm{C}=C$. $\mathrm{cf}$. major; $\mathrm{D}=C$. sp3; $\mathrm{F}=C$. sp2). The genus symplesiomorphies and synapomorphies, which were identified by inferring morphological characters on the time-calibrated phylogeny, are shown on the left. Abbreviations: PNG, Papua New Guinea. Image rights: Payri, C.E

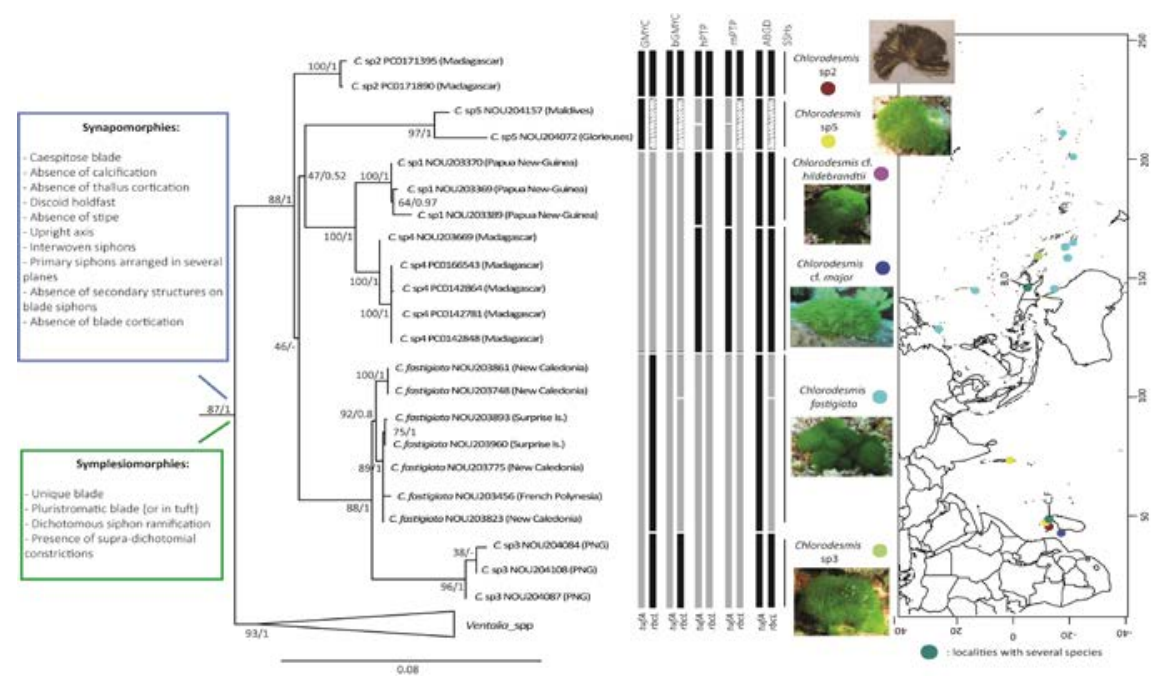

This article is protected by copyright. All rights reserved. 
Figure 7. ML phylogeny of Ventalia gen.nov. Bootstraps and Posterior probabilities (bs/PP) are indicated at nodes. Species hypotheses obtained using the five species delimitation methods on the two markers are presented on the right, along with allocated species names, illustrations and geographical distribution $(\mathrm{A}=V$. $\mathrm{sp} 1 ; \mathrm{D}=V$. orientalis; $\mathrm{E}=$ $V$. sp2.; $\mathrm{H}=V$. sp4). The genus symplesiomorphies and the synapomorphy, which were identified by inferring morphological characters on the time-calibrated phylogeny, are indicated on the left. Image rights: Payri, C.E.; Lasne, G.

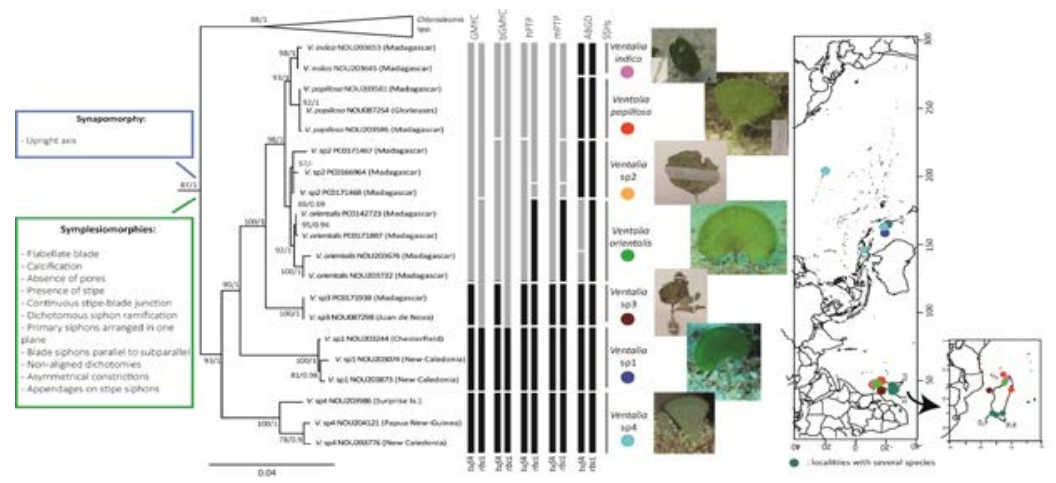

Figure 8. Ventalia genus. A-D, Ventalia indica (NOU203645-8). A, Herbarium specimen. B, In situ specimen. C, Blade siphons with protuberances. D, Stipe siphon with dichotomously divided appendages. E-H, Ventalia orientalis (NOU203718-722; NOU203680; NOU203683). E, Herbarium specimen. F, In situ specimen. G, Smooth blade siphon. H, Stipe siphon with dichotomously divided appendages. I-L, Ventalia papillosa (NOU203603; NOU203587). I, Herbarium specimen. J, In situ specimen. $\mathbf{K}$, Blade siphons with protuberances. $\mathbf{L}$, Stipe siphon with dichotomously divided appendages. Scale bars: $B=3 \mathrm{~cm} ; \mathrm{C}=80 \mu \mathrm{m} ; \mathrm{D}=65 \mu \mathrm{m} ; \mathrm{F}=0.8 \mathrm{~cm} ; \mathrm{G}=80 \mu \mathrm{m} ; \mathrm{H}=$ $65 \mu \mathrm{m} ; \mathrm{J}=0.7 \mathrm{~cm} ; \mathrm{K}=80 \mu \mathrm{m} ; \mathrm{L}=120 \mu \mathrm{m}$.

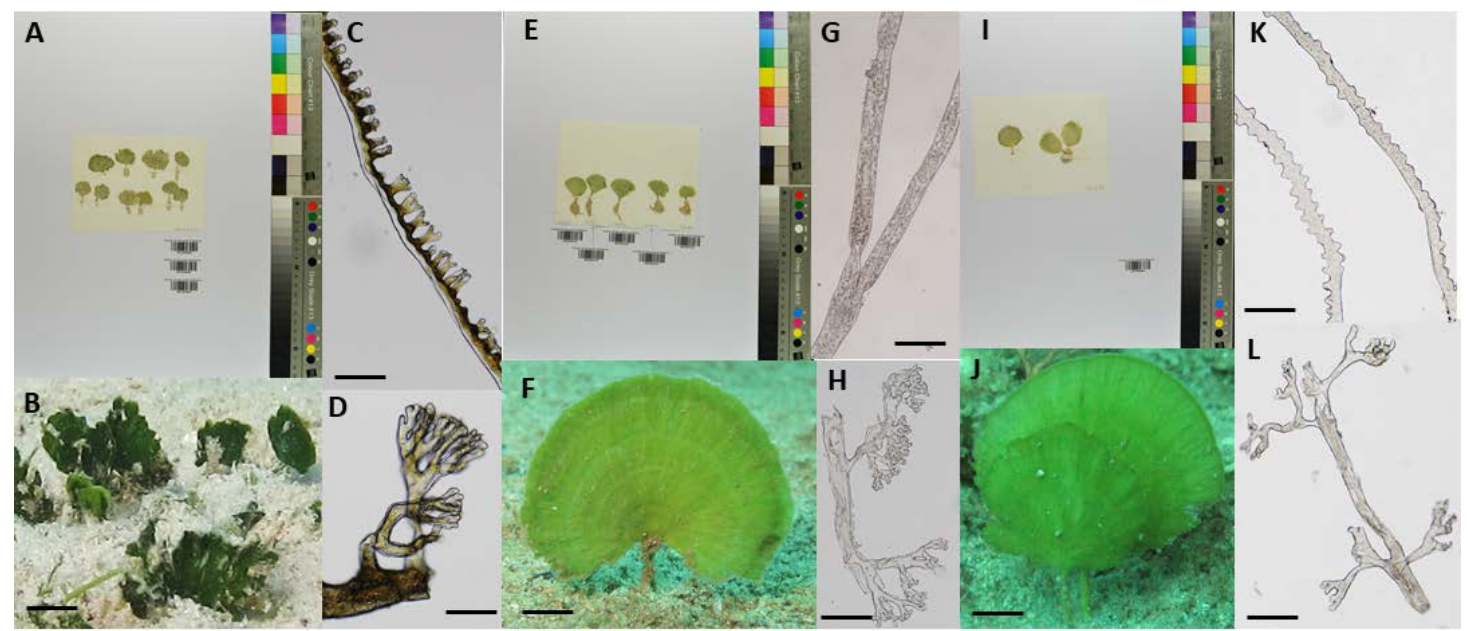

This article is protected by copyright. All rights reserved. 
Figure 9. ML phylogeny of Rhipidosiphon. Bootstraps and Posterior probabilities (bs/PP) are indicated at nodes. Species hypotheses obtained using the five species delimitation methods on the two markers are shown on the right, along with allocated species names, illustrations and geographical distribution $(\mathrm{B}=R . \operatorname{sp} 4 ; \mathrm{D}=R$. javensis). The genus symplesiomorphies and synapomorphies, which were identified by inferring morphological characters on the time-calibrated phylogeny, are shown on the left. Image rights: Payri, C.E.; Lasne, G, Coppejans et al. $\left(2011 ;{ }^{*}\right)$.

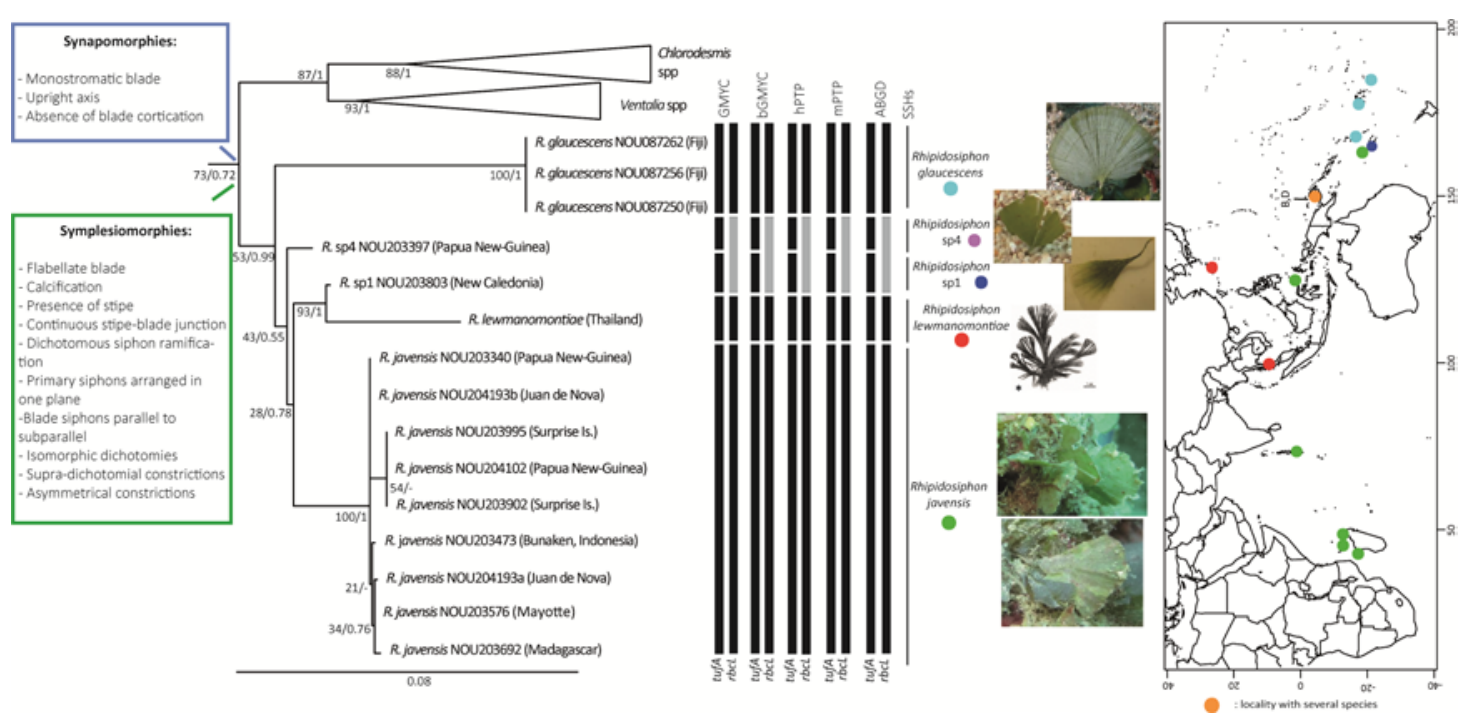

Figure 10. Udoteopsis maiottensis (NOU203562; NOU203570; PC0171655). A, Herbarium specimen. B, Specimen with corticated stipe and growth zone at the margin. CE, Frond. C, Smooth siphon; asymetrical dichotomies with constricitions. D, Calcificed siphons sheath with pores or cracks. E, Growth zone with swollen siphons. F-H, Corticated stipe with protuberances. Scale bars: $B=0.75 \mathrm{~cm} ; \mathrm{C}=125 \mu \mathrm{m} ; \mathrm{D}=16 \mu \mathrm{m} ; \mathrm{E}=120 \mu \mathrm{m} ; \mathrm{F}=$ $250 \mu \mathrm{m} ; \mathrm{G}=415 \mu \mathrm{m} ; \mathrm{H}=250 \mu \mathrm{m}$.

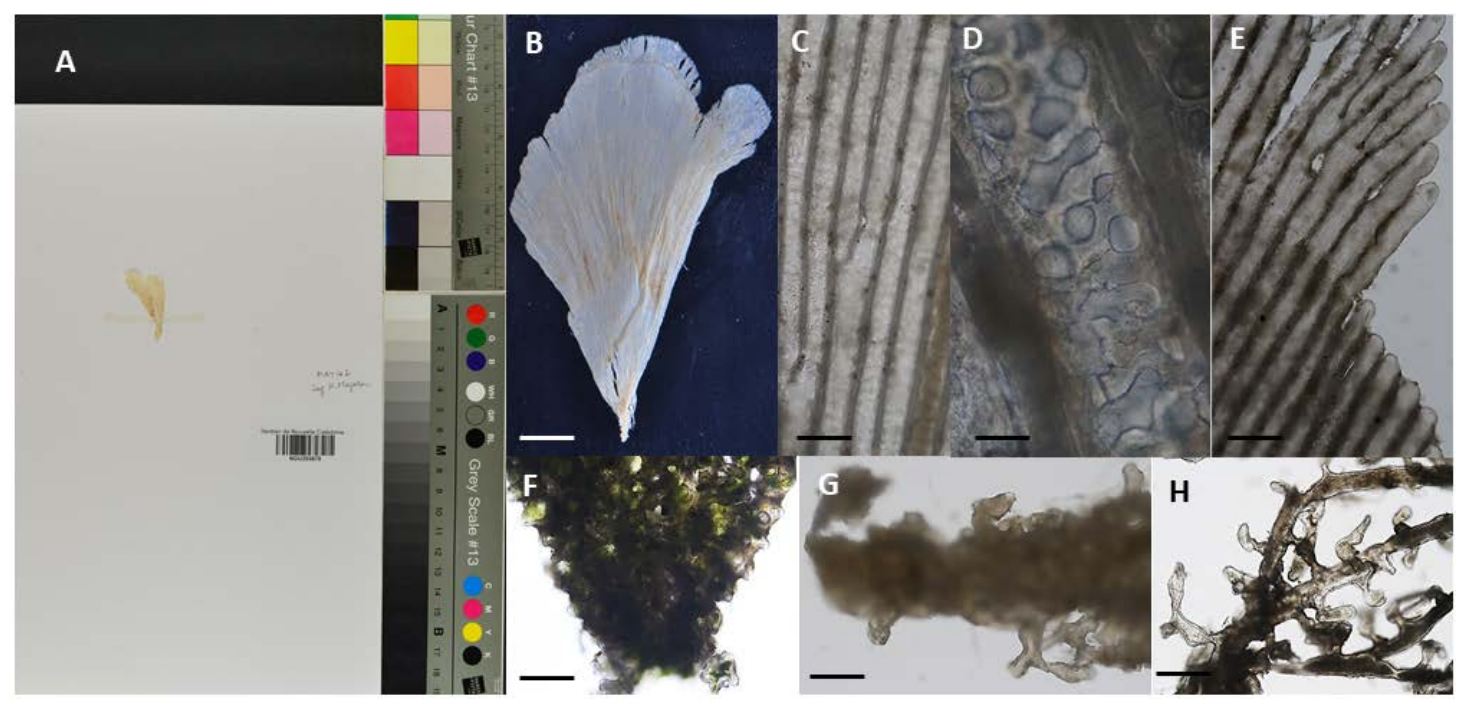

This article is protected by copyright. All rights reserved. 